مجلة جامعة الملك عبدالعنيز: الاقتصاد الإسلامي، م31 ع3، ص ص: 3-29 (محرم 1440/ أكتوبر 2018) DOI: 10.4197 / Islec. 31-3.1

\title{
صكوك المشاركة التفضيلية في الإيراد
}

\author{
محمد أنس الزرقا، محمد إبراهيم السحيباني، نادر أحمد النيفر \\ كبير المستشارين، شسركة شـورى، الكويت \\ أستاذ، أستاذ مشارك
}

كلية الاقتصياد والعلوم الإد/رية، جامعة الإمام محمدل بن سعود الإبسلامية، الرياض

المستخلص. إن صيغ المشاركة في الإيراد (المبيعات أو الناتج) هي امتدادٌ لعقود المزارعة والمساقاة

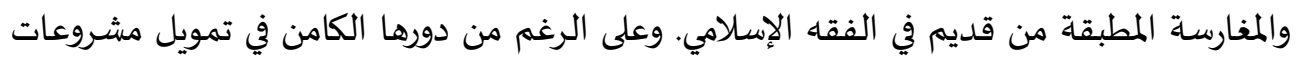

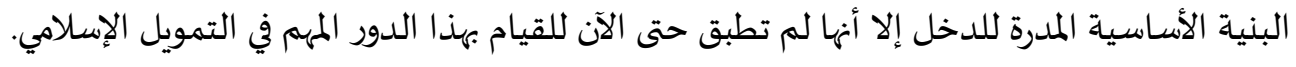

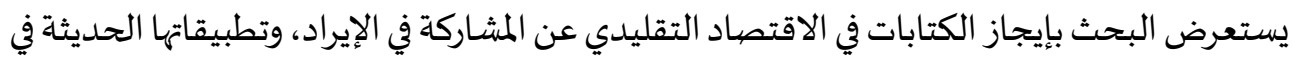
مجال الشراكة بين القطاعين العام والخاص لتمويل إنشاء وتشغيل مشروعات البنية الأساسية.

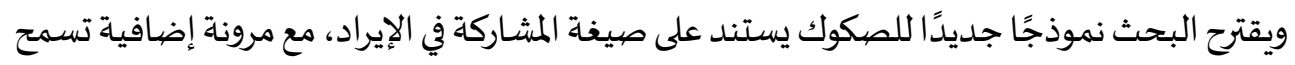

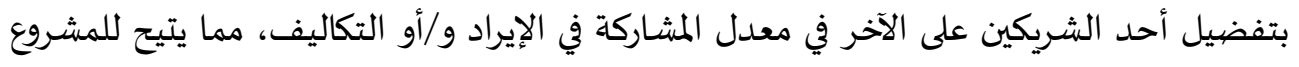

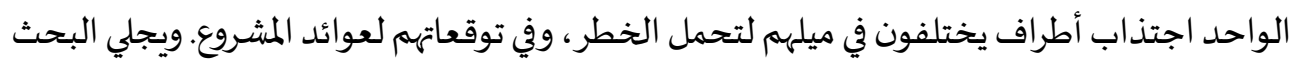

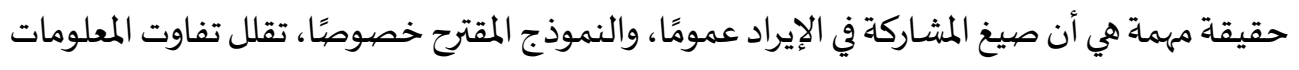

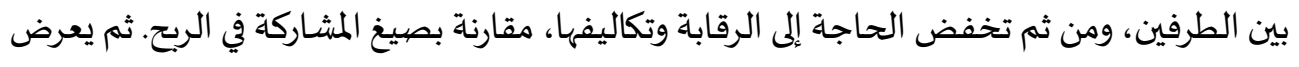
البحث تطبيقات تلك الحقيقة ومزاياها، والإشكالات الفقهية والاقتصادية العديدة التي تثيرها وتحتاج

إلى دراسات مستقبلية مستقلة.

الكلمات الدَّالة: صكوك، المشاركة في الإيراد، مشروعات البنية الأساسية، المزارعة، المساقاة، المغارسـة، الشراكة بين القطاعين العام والخاص، تفاوت المعلومات بين الطرفين.

تصنيف H54, D86, D82:JEL تصنيف K13, K6, R35:KAUJIE 


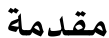

يهدف البحث إلى استطلاع إمكانيات هذه الصيغة في التمويل، وفرص استخدامها كأساس للتصكيك، وبخاصة

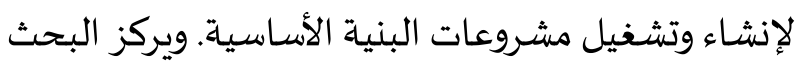
تحديدًا على بيان طريقة تفضيل أحد الشريكين على الآخر في معدل المشاركة في الإيراد و/أو التكاليف، حسب مستوى الإيراد والتكاليف، وذلك تعميمًا لمفهوم الأسهه

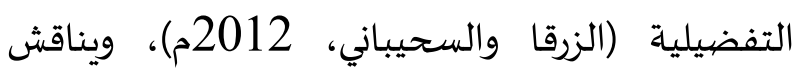
البحث أيضًا الإشكالات التي قد تثور في هذه الحالة. ومن أبرز الإضيافات التي يقدمها البحث مقارنة

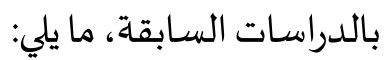
1. تقديم صيغة مقبولة فقهًا للمشاركة في الإيراد،

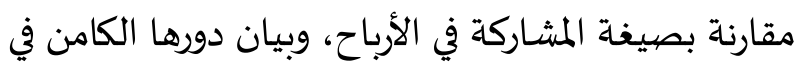
تخفيض تكاليف الرقابة في التمويل، وهي قضية جوهرية في التمويل بالمشاركة.

2. إيضاح الموقف الفقهي من الصيخ المختلفة مع الإيجاز والتعليل بطريقة مفهومة للاقتصاديين، وتحديد مسائل جديرة بمزيد من البحث للوصول لحكمها الشرعي. 3. تقديم صيخ مبتكرة للمشاركة في الإيراد مع تفضيل أحد الطرفين، وبيان بعض مزاياها في إطار تفاوت

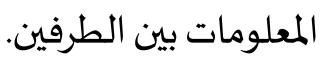

وتنبع أهمية البحث من عظم الآثار الخارجية لصيخ

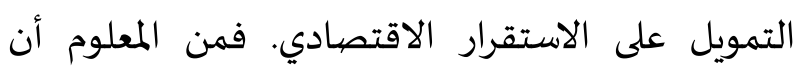
للتمويل طريقين لا يستغني الاقتصاد عن أي منهما؛ وهما المداينات والمشاركات. ولكل من الطريقين في الشريعة صيفًا مباحة وأخرى ممنوعة. وقد اتجهت اقتصادات المجتمعات الغربية - وتبعتها مجتمعات أخرى - منذ خمسينيات القرن العشرين إلى زيادة نسبة التمويل بالمداينات (الربوية
إن من أبرز صيخ التمويل التي لم تطبق حتى الآن من قبل المؤسسات المالية عقود المشاركة في الإيراد (المبيعات أو الناتج). وتعد صيخ المشاركة في الإيراد تعميمًا لعقود المزارعة والمساقاة والمغارسة المعروفة من قديم في الفقه لماته الإسلامي. وقد أصدرت هيئة المحاسبة والمراجعة للمؤسسات المالية الإسلامية (أيوفي) معيارًا خاصيًا بالمسساقاة (المعيار 50)، وتُعد حاليًا معيارًا خاصيًا بالمزارعة. كما تضمن معيارها الخاص بصكوك الاستثمار (المعيار 17) صكوك المزارعة والمساقاة والمغارسـة، ولكن حسب المبارها علمنا لم تطبق حتى الآن في الأسواق المالية الإسلامية. ومن المهم أن نشير في البداية إلى أن المشاركة في الإيراد هي من باب تسمية الكل باسم البعض، لأها تتضمن في كثيرٍ من الحالات مشاركة في الإيراد والتكاليف. أي أن بالن الطرفين لا يكتفيان في الغالب بالمشاركة في الإيراد فقط بل يتشاركان أيضًا في التكاليف بنسب وآليات مختلفة. وسنرى في ثنايا البحث أن المشاركة في الرتح هي حالة خاصة للحالة التي تتساوى فيها مشاركة الطرفين في كلٍ من الربح والتكاليف. والفرق الرئيس بين ما نسمياء مشاركة في الإيراد ومشاركة في الربح، أن الاتفاق يقع على الريح فقط (الإيراد

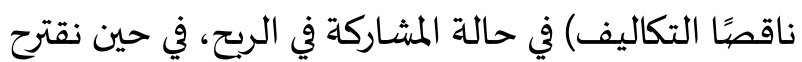
في هذا البحث جواز أن يقع على الإيراد وعلى التكاليف، كل على حدة، وبنسب مختلفة في حالة المشاركة في الإيراد والتكاليف. وهو ما يمنح أطراف المشاركة مرونة أكبر للتفاوض واختيار صيغة أمثل للتعاقد تتناسب مع قدرات الشركاء على مراقبة بنود التكاليف المختلفة ، ومع توجهاتهم المختلفة تجاه تحمل المخاطر. وعلياء، فإن مصطلح المشاركة في الإيراد في العنوان ومتن البحث يشمل أيضًا الصيخ التي تتضمن مشاركة في الإيراد والتكاليف. 
الاقتصادية. وكلما قلت الأمانة أو زادت الحاجة للرقابة Khan, 1989: ) وتكاليفها، رجحت كفاءة التمويل بالمداينة

وعليه، فإن كل ما يسـاعد على تقليل تكاليف الرقابة يمهد الطريق أمام المشاركات ويرغب الناس فيها، مما ينفع أطراف العقد ويفيض على المجتمع. ويجلي هذا البحث حقيقة اقتصادية مهمة هي أن صيغ المشاركة في الإيراد تقلل الحاجة إلى الرقابة وتخفض تكاليفها، مقارنة بصيغ المشاركة في الربح. ثم يقدم نتائج وتطبيقات لتلك الحقيقة. يبدأ البحث باستعراض عام لكتابات الاقتصاديين حول المشاركة في الإيراد، ثم نشير لتطبيقاتها الحديثة في

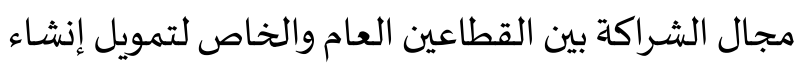
وتشغيل مشروعات البنية الأساسية، ثم نعرض بشكل مختصر لعقود المشاركة في الإيراد في الفقاء تمهيدًا لتقديم لمهيل نموذج مقترح لصكوك تفضيلية تستند على صيغة المشاركة في الإيراد. وفي الختام نناقش عددًا من المسائل المهمة التي يثيرها هذا النموذج.

1 - المشاركة في الإيراد: الدراسـات السابقة يوجد عددّ كبيرُ من الأبحاث التي تناولت المشاركة في الإيراد في عقود التمويل، والتي عادة ما تفرد تحت عنوان مشاركة الإنتاج الزراعي أو المزارعة (Sharecropping). ومن الملفت أن Joseph Stiglitz من الرواد الذين كتبوا عن هذا الموضوع، حيث قدم (Stiglitz, 2013) تحليلاً لإسسهاماته وآخرين في موضوع مشاركة الإنتاج الزراعي أخذًا في الاعتبار التطورات التي حصلت في علم الاقتصاد منذ السبعينيات، وخاصة في مجال نظرية التعاقد وتفاوت المعلومات بين طرفي العقد، وأثر ذلك على الحوافز وتوافق مصالح الشركاء. ومن واقع هذه الدراسة والدراسات المسحية الأخرى التي استعرضت تطور الكتابات في هذا
عادة) إلى مجموع التمويل، على حساب التمويل بالمشاركات. وشجعت النظم الضريبية هذا الاتجاه، الذي تسارع كثيرًا لأسباب متعددة منذ السبعينيات من القرن الماضي حتى بلغ مستويات قياسية قبيل وقوع الأزمة المالية عام 2008م، حيث كان ذلك من أهم أسبابها. وقد أبرزت تلك الك المات

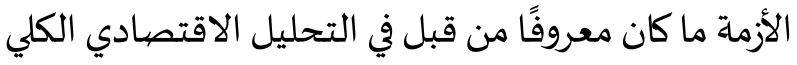
لكن تم تجاهله في السياسات العامة، من أن الإفراط في التمويل بالمداينات له آثار خارجية ضارة تصيب غير غير طرفي

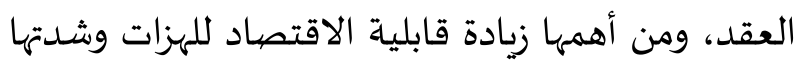
حين تقع. على العكس من التمويل بالمشاركات الذي يُحصن من الهزات ويخفف وقعها، فضلاً عن انه أكثر من لئر عدالة. ويقدم (ميلز وبريسلي، 1435هـ: 211-213) حججًا قوية ضد التمويل بالمداينات مبنية على آثارها الخارجياة، ويثبت أن التمويل القائم على القرض بفائدة يفرض تكاليف على المجتمع برمته، وأنها عالية بما يكفي لتبرير تقييد الحرية الاقتصادية.

في ضوء ذلك، تعالت بعد الأزمة أصوات الاقتصاديين والمؤسسات الدولية المنادية بتقليل الاعتماد على المداينات وسيلة للتمويل، وبإحلال المشاركات محل المداينات ما أمكن. لكن التمويل بالمشاركات يواجاه في التطبيق عقبات من أبرزها اتساع مجال الخيانة في المشاركات من قبل الشريك المدير الذي يعرف التكاليف والإيرادات والأرباح (أو الخسائر) التي حققها المشروع فعلاً، لكنه يستطيع الكتمان والتغيير. وهذا ما تسمياء اقتصاديات العقود: المخاطرة الأخلاقية نتيجة تفاوت المعلومات بين الشريك ومك ماتك الممول والمدير. وللتوقي من الخيانة لا بد من رقابة على المدير لها تكاليف لا يُستهان بها، قد تذهب بمزايا المشاركة وتُزَِّّدُ الناس فهيها. ويدل التحليل الاقتصادي عممومًا على أنه كلما كان الشركاء أمناء، أو كانت تكاليف الرقابة قليلة نسبيًا، فإن المشاركة تفوق المداينة من حيث الكفاءة 
4. تحدد اتفاقية المشاركة في الإيراد نسبة المشاركة في

الناتج، والتي تعتمد فيما تعتمد على نسبة ما يتحمله كل طرف من تكاليف الإنتاج. وقد تطرقت بعض الأبحاث

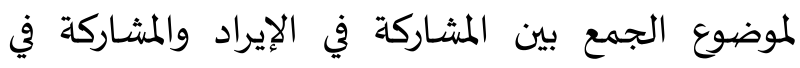
التكاليف وأثر ذلك على كفاءة عقد المشاركة. ومن النتائج المتفق عليها أن تساوي نسبة المشاركة في الإيراد مع نسبة

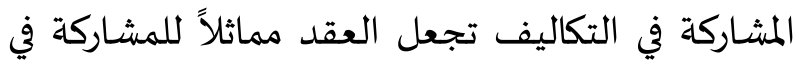
الريح بالنسبة نفسها (انظر إثبات ذلك في الحالة الرابعة

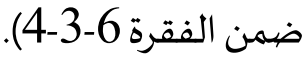

5. من المتوقع اقتصاديًا أن يطالب من يقدم مدخلات أكثر بنسبة مشاركة أعلى في الإيراد. ومع ذلك، تظل هناك مشكلة تتعلق بقدرة الطرفين على مشاهدة ومراقبة التكاليف أو الإيراد. فهناك حالات يصعب فيها مشاهدة الإيراد (مثل سيارة أجرة يقدمها مالكها لعامل سائق لقاء حصة من الإيراد)، مع سهولة مراقبة التكاليف (البنزين والزيت والإصلاحات)، وأخرى يسهل فيها العكس (مثل

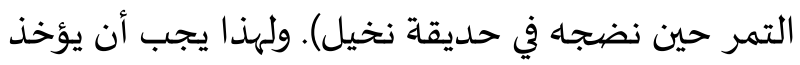

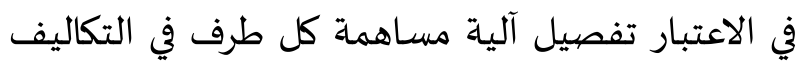
لتقليل المخاطر الأخلاقية؛ أي مخاطر الخيانة بلغة الفارة الفقهاء. ويمكن أن يتم ذلك من خلال تصميم العقد

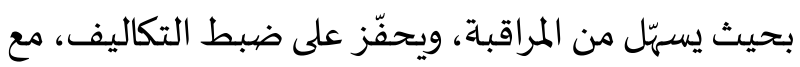
محاولة اختبار العقد قبل توقيعه لمعرفة الثغرات التي يمكن أن يحدث من خلالها التلاعب، واتخاذ الاحتياطات

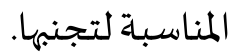

6. ذكر بعض الباحثين أن من تطبيقات المزارعة إضافة بند في العقد يضمن حدًا أدنى لما يحصل عليه المانيه

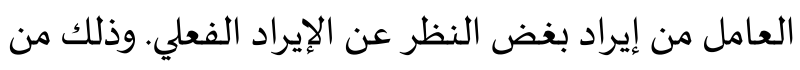

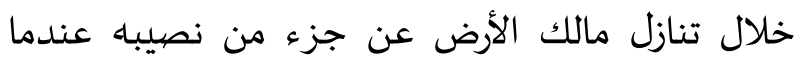
ينخفض نصيب العامل عن هذا الحد الأدنى. ومن وجهة نصية
الموضوع وخاصة (Sen, 2016) و(Singh, 1991)، يُمكن

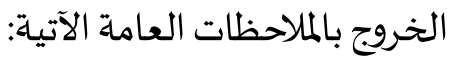
1. ركزت أوائل الأبحاث في موضوع مشاركة الإنتاج

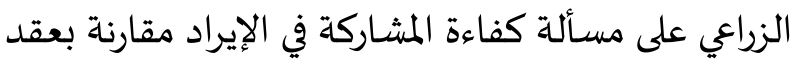

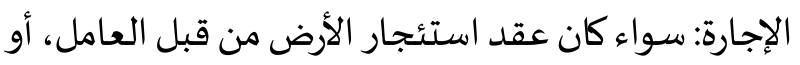
عقد استئجار خدمات العامل من قبل مالك الأرض. والكفاءة المقصودة هنا هي الكفاءة الاقتصادية التي تعني تقريبًا زيادة المنافع المولدة من كمية معينة من الموارد. فعند فئد المفاضلة بين وضعين ممكنين، يفضل الاقتصاديون أكثرهما كفاءة، إن استويا فيما سوى ذلك. 2. إن مصدر اختلاف النتائج حول كفاءة المشاركة مقابل الإجارة يرجع للافتراضات حول طبيعة الخطر

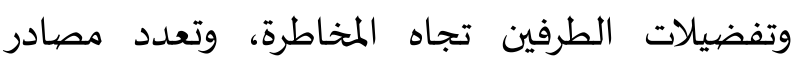
المخاطرة، وتأثير المشاركة على الحوافز. والماحلاحظ أن أوائل

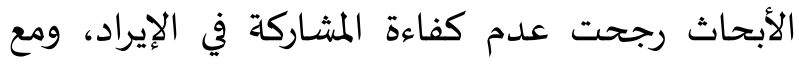
التقدم في نظرية التعاقد (contract theory) التي أَدخلت في صلب التحليل تفاوت المعلومات وأثر عقد المشاركة على الحوافز، ظهرت نتائج مخالفة تميل لتفضيل المشاركة على

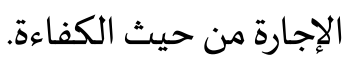
3. إن من أسباب تفضيل المشاركة في الإيراد على الإجارة أهها تؤدي إلى مشاركة الطرفين في تحمل مخاطر

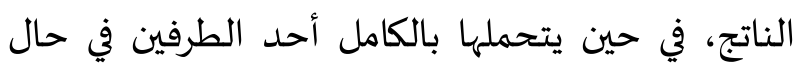
الإجارة، كما يمكن لعقد المشاركة في الإيراد في حال تصميمه بشكل جيد أن يكون له أثرُ أفضل على حافز الإيراد الشريك العامل، سواء من خلال المدفوعات الجانبية للعامل، أو تعديل العقد ليصبح غير (side payments) خطي (nonlinear)، وهو الذي يدفع فيه للعامل نسبة لإنا

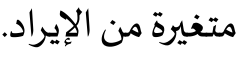


(Minimum Revenue Guarantee-MRG) الفرق بين هذا الحد والإيراد الفعلي إذا كان الفعلي أقل منه، على أن يذهب كل الإيراد فوق هذا الحد لشركة القطاع

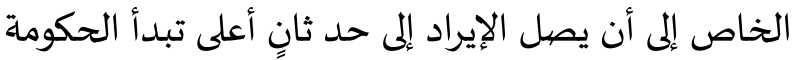
بعده في مشاركة القطاع الخاص في نسبة من الإيراد. وقد اصطلح على تسمية الحد الثاني بالحد الأقصى للإيراد Revenue cap) 2. بالنظر لطبيعة هذه الحوافز الحكومية، التي هي احتمالية وتعتمد على الإيراد الفعلي للمشروع، فقد توصل الباحثون إلى إمكان تقييمها بصفتها نوعًا من الخيارات

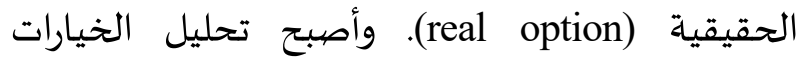
الحقيقية يدخل في صلب تقييم هذه المشروعات، لأناه يعطي تقييمًا أصيدق للمشروعات مقارنا بالطرق التقليدية المبنية على صافي القيمة الحالية ومعدل العائد الداخلي (انظر على سبيل المثال)(Ashuri et al., 2010). 3. هناك عدة أشكال للحوافز التي تقدمها الحكومة من خلال الإيراد؛ فقد تكتفي بعض الحكومات بالمشاركة

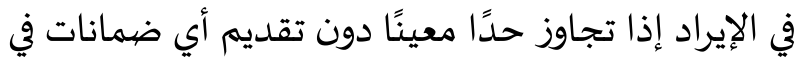

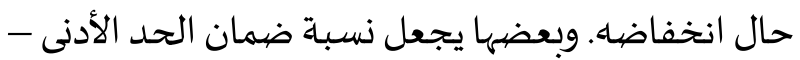
في حال تبنيه - متناقصة مع تقدم مدة امتياز المشروع، بحيث يُلغى بعد مضي مدة معينة.

4. تقسم مشروعات الشراكة بين القطاعين العام والخاص إلى نوعين: (1) مشروعات مجدية اقتصياديًا financially feasible، وهي قابلة للتمويل ومربحة للقطاع الخاص بدون الدعم الحكومي، ولهذا تحصل الحكومة على رسوم مقابل منح الامتياز، و(2) مشروعات غير مجدية

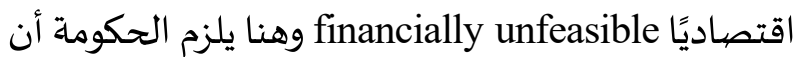
توفر حوافز لتحسين ربحية المشروع وجعله قابلاً للتمويل من وجهة نظر القطاع الخاص. (bankable)
نظر اقتصادية ينظر لهذا البند على أنه محفز للعامل للدخول في عقد المشاركة؛ لأناه يخفف من حدة المخاطرة التي يواجهها العامل، ويثبط في الوقت نفساه من رغبته لتبني تِقانات إنتاجية عالية المخاطر قد تضر بالأصل الإنتاجي.

7. تفترض أغلب الدراسـات السابقة أن عقد المشـاركة خطي (بمعنى أن الحصص النسبية لأطراف العقد ثابتة)؛

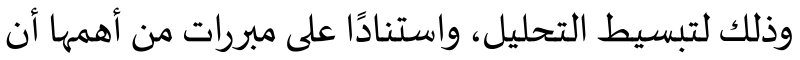
هذا هو المشـاهد في أغلب تطبيقات العقد على أرض الواقع. 8. ركزت كتابات كثيرة على تأثير المشاركة في الإنتاج الزراعي على حافز العامل، لكن نهت دراسات أخرى إلى أن إن إنات هناك قرارات أخرى تؤثر على الناتج بالإضافة إلى جهد العامل، وتتعلق ببقية المدخلات المطلوبة والتِقانة التي ستستخدم في العملية الإنتاجية. 2 - تطبيقات المشـاركة في الإيراد في مشروعات الشر اكة بين القطاعين العام والخاص على الرغم من تركيز أكثر الدراسات السابقة على تطبيقات المشاركة في الإنتاج الزراعي، إلا أن هناك اتجاهًا

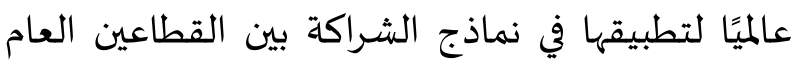
والخاص (Public-Private Partnership)، والذي فتح بـ بدوره مجالاً جديدًا للباحثين لدراسة هذه التطبيقات.

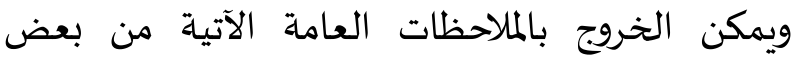
الدراسات التي استعرضت التطورات في هذا المجال وخاصة (Verdouw, 2015): 1. الملاحظة الرئيسة أن المشاركة في الإيراد في هذه المشروعات تكون بمعدل متغير أو غير خطي (nonlinear)؛

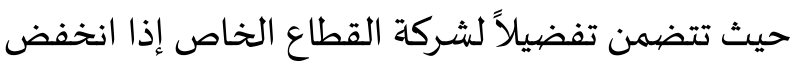
الإيراد عن حد معين تحفيزًا لها للدخول في هذه المشروعات. وأبرز شكل لهذا التفضيل هو ضهمان حد أدنى من الإيراد 
مال نقدي. ونستعرض هنا النموذج الذي يتبناه موقع المتخصص (www.lightercapital.com) lighter capital في توفير هذا التمويل للمشاريع التِقانية الناشئة. وتقوم هذه الصيغة على تمويل المشروع بمبلغ نقدي مقابل حصة ثابتة من الإيراد إلى أن يتم استعادة كامل

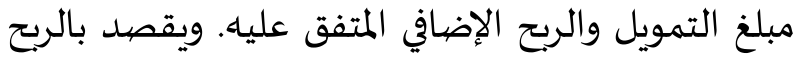
الإضافي الزيادة على أصل مبلغ التمويل التي سيسددها

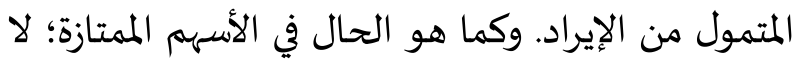
يؤدي التمويل إلى التدخل في إدارة الشركة ولا إلى التزام

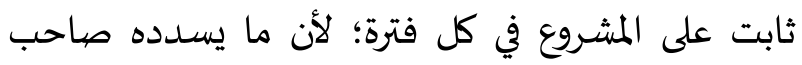
المشروع للممول يمثل نسبة من الإيراد الشهري التي يتقلب من شهر لآخر. في المقابل، تتفوق هذه الصيغة على الأسهم لإنيه الممتازة من وجهة نظر المتمول بأها لا تؤدي إلى تملك الممول لأي حصة في الشركة، ولن يكون له من ثم أي سلطة في مجلس إدارتها. وحسب نموذج موقع lighter capital لا يزيد حجم التمويل عادة عن ثلث الإيراد السنوي المتوقع للشركة المتمولة، ويتراوح بين 500 ألف و2 مليون دولار. كما

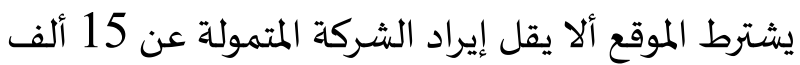
دولار سنويًا، وألا يقل هامش الريح الإجمالي عن 50\%

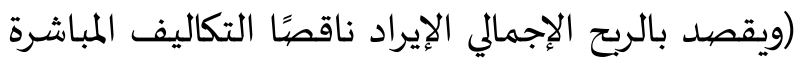
فقط). أما النسبة التي يجب على المتمول تسديدها شهريًا فلا تزيد عن 10\% من الإيراد الشهري. وفيما يتعلق بمعدل

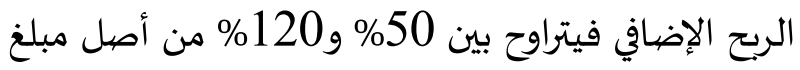

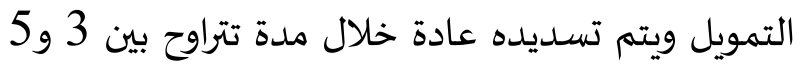
سنوات. ويوضح الشكل (1) آلية عمل المشاركة في الإيراد بتمويل نقدي خلال أول (15) شهرًا في عقد التمويل،

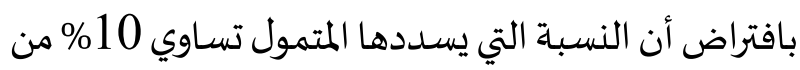

5. كلما التزمت الحكومة بتحمل نسبة أكبر من المخاطر في صورة ضمانات أكبر، جذبت عددًا أكبر من الشركات التي تتنافس على تنفيذ المشروع، وتعرض على الحكومة رسوم

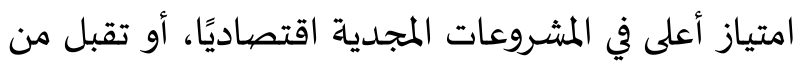
الحكومة تحمل نسبة أقل من تكاليف المشروع أو تقديم إعانات أقل في المشروعات غير المجدية. وعليه، فإن المشاركة في الإيراد مع ضمانات حكومية هي وسيلة للوصول إلى عقد إلد الميات أمثل تتم فيه مشاركة مثلى للمخاطر بين الطرفين، وهو ما يتم التعبير عنه بالحل الذي يعظم قيمة ما ينفق على

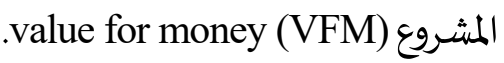
6. في حال التزام الحكومة بتقديم إعانات محتملة

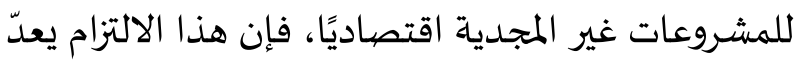

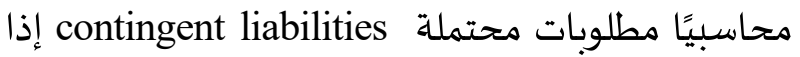
كان احتمال وقوعها متوسطًا إلى مرتفع، وكانت قابلة للتقدير. وهو ما يتطلب تطوير آلية لتسعير هذه الالتزامات، ومعايير للموافقة علهها من قبل الحكومة، ثم مراقبتها وإدارة مخاطرها. وكان من جملة الآليات التي اقترحت لإدارة مخاطر السيولة التي قد تنشأ من وقوع هذه المطلوبات: إنشاء صندوق للمطلوبات المحتملة يتم تغذيته من ميزانية الحكومة ومشروعات الشراكة. وقامت دول عديدة بإنشاء مثل هذا الصندوق تحت مسميات مختلفة، بهدف زيادة ثقة المستثمرين ووكالات التصنيف بقدرة

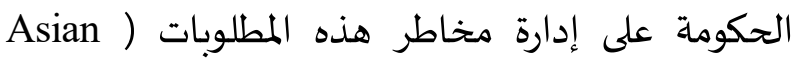
(Development Bank, ADB, 2016: 53-60 3- تطبيقات المشاركة في الإيرادفي مشروعات رأس المال الجريء لم يقتصر تطبيق المشاركة في الإيراد على نماذج

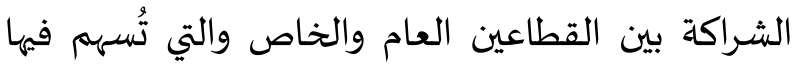
الحكومة برأس مالٍ ثابتٍ، بل امتدّ إلى مجالات أخرى منها

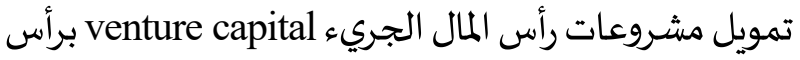


الإيراد الشهري. وأن مبلغ التمويل 50 ألف ريال، و أن الشهري للمتمول 15 ألف ريال، فالمتوقع أن ينتهي من معدل الريح الإضافي 50\% ( مما يعني أن المتمول سوف تسديد مبلغ التمويل والريح الإضافي خلال (50) شهرًا. يسدد 75 ألف ريال)، وبافتراض أن متوسط الإيراد

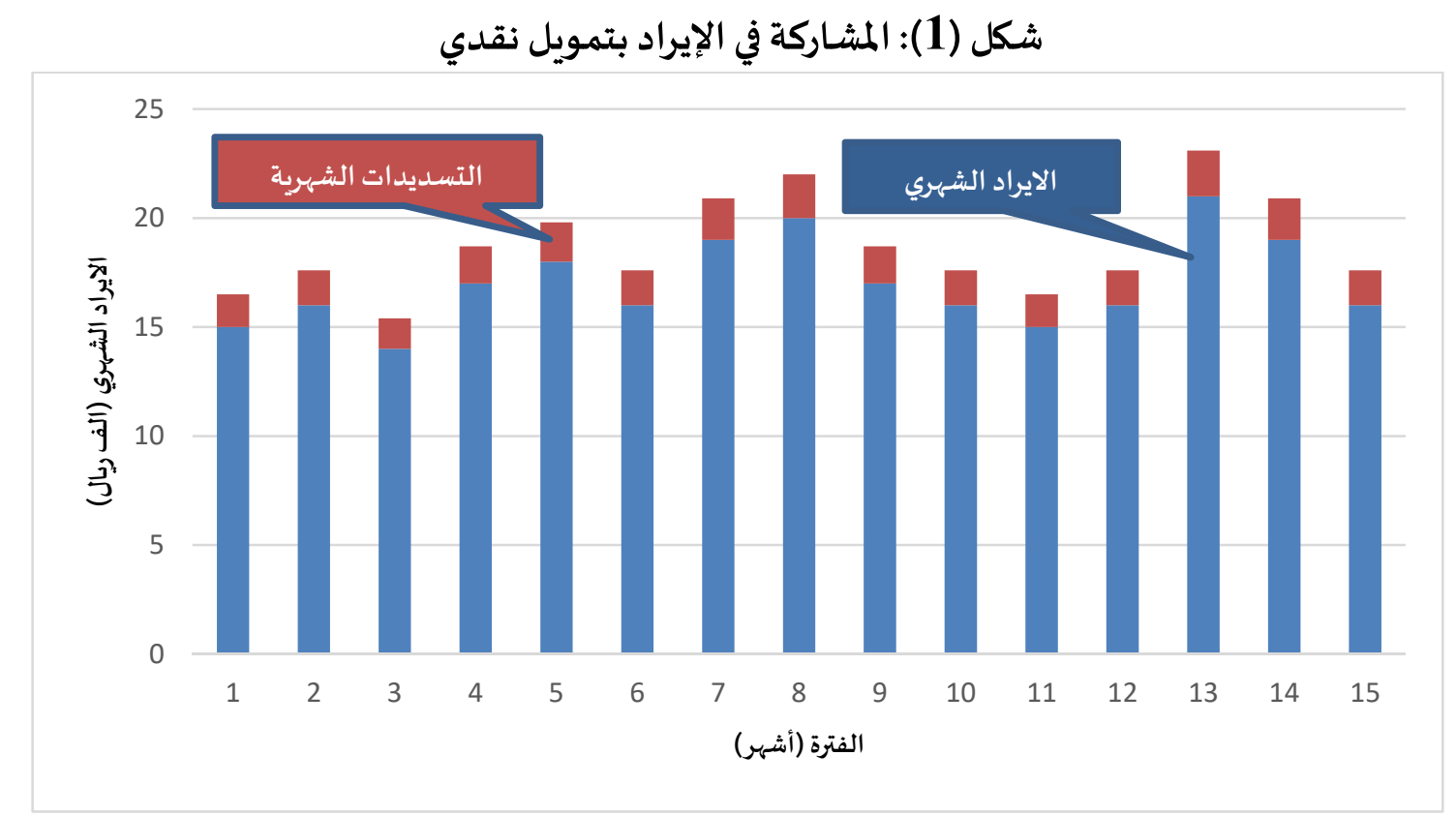

المصددر:www.lightercapital.com

ويلحظ هنا تشابه المزارعة مع المساقاة بجامع حصول

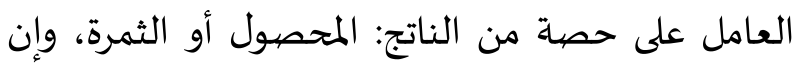
العامل فيهما - كما سنفصل بعد قليل - لا يتحمل إلا تكاليف متغيرة. ولا يجوز في أي من العقدين اشتراط تحمل العامل أية نفقات استثمارية تتجاوز منافعها مدة العقد، كحفر بئر أو بناء سور. لكن تختلف المزارعة عن المساقاة

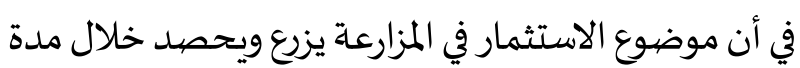
عقد المزارعة، أما المساقاة فتتضمن خدمة أصل ثابت فرابت موجود يتوقع أن يبقى بعد انقضاء مدة المساقاة.

أما المغارسة فتختلف عن المزارعة والمساقاة بشكل جوهري، إذ العامل فهها يقدم، بالإضافة للعمل، استثمارًا هو غِراس أشجار مثمرة (جمع غريسة وهي الفسيلة)

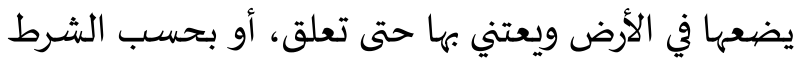

4- المشاركة في الإيراد في الفقه الإسلامي: بالإضافة إلى عقود المشاركة في الريح، يتفق معظم الفقهاء على مشروعية ثلاثة عقود تمثل أساسًا للمشاركة

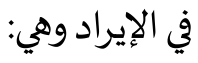

1. المزارعة: وهي عقد بين العامل ورب الأرض يشترك بموجبه الطرفان في المحصول الذي يزرعه العامل. 2. المساقاة: وهي عقد بين العامل ورب الأرض ذات الأشجار المثمرة، يشترك بموجبه الطرفان في ثمرة الأشجار

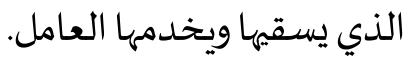

3. المفارسة: وهي عقد بين العامل ورب الأرض يشترك بموجبه الطرفان في الأرض والأشجار الذي يغرسها العامل. 
راجع الموسوعة الفقهية، 56/37). وقد صححت مذاهب فقهية صبورًا متنوعة للمزارعة، تختلف فيها نسبة مشاركة الطرفين في التكاليف ومن ذلك (الموسوعة الفقهية، :68-65/37

1. أن يكون العمل من جانب، والباقي كله من أرض وبذر وماشية وآلات ونفقات من الجانب الآخر. 2. أن تكون الأرض من جانب، والباقي كله من الجانب الآخر. 3. أن تكون الأرض والبذر من جانب، والعمل والماشية

$$
\text { من الجانب الآخر وهو المزارع. }
$$

4. أن يتساويا في الجميع، أرضًا وعملاً وبذرًا وماشية ونفقات. 5. أن يقابل بذر أحدهما عمل من الآخر، وكانت الأرض مشتركة بينهما، وتساوت قيمة العمل والبذر. 6. أن يقابل الأرض وبعض البذر عمل من الآخر مع

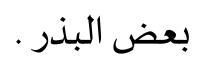

7. أن تكون الأرض والماشية من جانب، والعمل والبذر

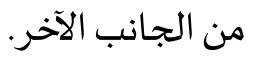

8. أن يكون البذر والدواب من جانب، والأرض والعمل

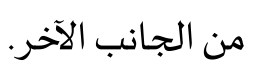

9. أن يكون البذر من طرف، والباقي كله من الطرف الآخر.

وعند تفصيل بنود العمل رتب الفقهاء على المزارع كل عمل يحتاج الزرع إليه لنمائه وصلاح حاله كالري والحفظ وتطهير المراوي الداخلية والتسميد، وحرث الأرض إذا

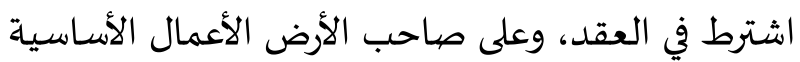
التي يبقى أثرها ومنفعتها إلى ما بعد عقد المزارعة كبناء حائط وإجراء الأهار الخارجية ونحو ذلك. وعلى وملى المزارع وصاحب الأرض معًا كل ما كان من باب النفقة على الزرع، ويكون ذلك على قدر حقهما كثمن السماد وقلع الحشائش
حتى تثمر، فمتى تحقق ذلك صار له الحصية المتفق عليها في الأرض والغرس. وهذا رأي المالكية، ويرى الحنفية والحنابلة جواز المغارسة على سبيل الشركة في الشجر والثمر فقط دون الأرض (الموسوعة الفقهية، 174/31). ومن خلال متابعة تنظيم هذه العقود في بعض القوانين العربية، اتضح وجود عقد جديد مماثل لعقد المغارسـة وهو عقد المساطحة. وهو عقد بين مالك الأرض والمساطِح لمدة طويلة نسبيًا (30-50 سنة)، يظل المساطِح خلالها مالكًا لكل ما يبنيه عليها، مقابل مبلغ يدفع سنويًا لمالك الأرض.

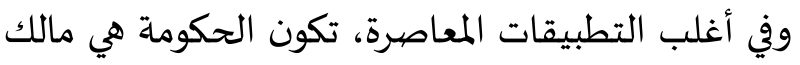
الأرض، والمساطِح مستثمر من القطاع الخاص. ووجها

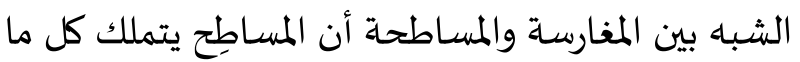
يبنياه على سطح الأرض، كما يتملك المغارس جزء من الشجر الذي يغرساه في الأرض (الأسعدي، 2015). وباستعراض آراء المذاهب الفقهية في هذه العقود وخاصة فيما يتعلق بواجبات طرفي العقد، يتبين كما أشرنا في المقدمة أن المشاركة ليست محصيورة أن تكون في الإيراد، بل يمكن أن يتشارك الطرفان أيضًا في التكاليف. وتبعًا لذلك، تتمتع هذه العقود بمرونة أكبر من عقود المشاركة في الربح فيما يتعلق بمن يتحمل بعض أنواع العمل والآلات

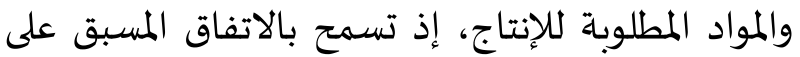
شروط تقسيم التكاليف بحيث يختص العامل بمهام معينة ورب الأرض بمهام أخرى، أو يشتركان فيها (الموسوعاة

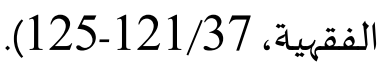
ففي المزارعة يوجد خلاف مشهور بين الفقهاء في الطرف الذي يكون عليه البذر، هل يجوز أن يكون من

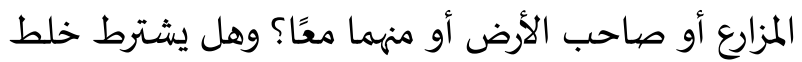

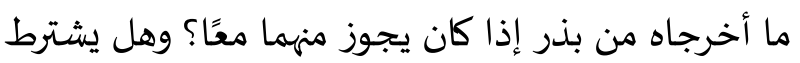
تماثل البذرين جنسًا وصنفًا في هذه الحالة؟ (للتفاصيل: 
2. على رب المال ما فياه حفظ الأصل، كإنشاء الأههار

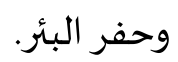

3. كل ما يتكرر كل عام فهو على العامل وما لا يتكرر

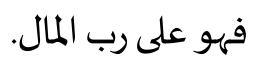

4. ألا يكون ما على رب المال أكثر العمل، لأن العامل يستحق بعمله فإذا لم يعمل أكثر العمل كان وجود عمله كعدماه فلا يستحق شيئًا.

الشافعية:

قسم الشافعية العمل في المساقاة إلى أربعة أضرب

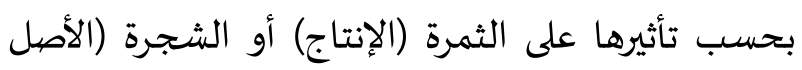
المنتج). ويوضح الشكل (2) هذه الأقسام.

ولهذا التقسيم انعكاساته المباشرة على ما يلزم كل طرف من العمل، ونصيبه من تكاليف مدخلات الإنتاج. وقد اعتبر معيار هيئة المحاسبة والمراجعة للمؤسسات المالية الإسلامية (AAOIFI) الخاص بالمساقاة (المعيار الشرعي رقم 50) أن "النفقات المتعلقة بالمساقاة على المساقي ومالك الشجر بقدر حصصيهما مالم يتفقا على بلى خلاف ذلك" (المادة 2/8). وذكر المستند الشرعي لهذا التقسيم "أنه أقرب إلى تحقيق العدالة؛ حتى لا يقع ضرر

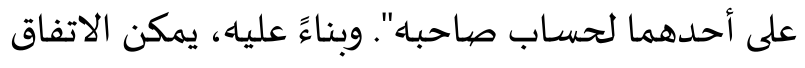
المسبق بين الطرفين على نسبة تقاسم الإيراد وعلى نسبة

$$
\text { أخرى لتقاسم التكاليف. }
$$

والذي يتحصل مما سبق ذكره من اجتهادات الفقهاء

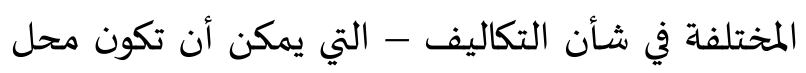
اشتراك الطرفين أو ينفرد أحدهما بتحملها - هو اتفاقهم

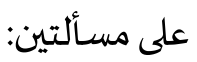
• أن التكاليف تقتصر على المدخلات المفيدة لعمليـة

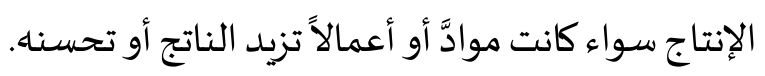

المضرة، وعليهما أيضيا أجرة الحصياد، وحمل المحصول إلى

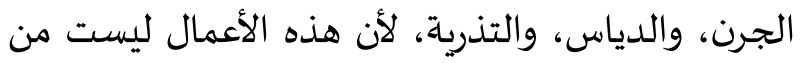
أعمال المزارعة حتى يختص بها المزارع وحده (الموسوعة الفقهية 71-70/37). وفيما يتعلق بالمساقاة، أشار الفقهاء إلى عدة معايير للتفريق بين واجبات الطرفين في عقد المساقاة، والتي يمكن باءن تلخيصها فيما يلي (للمزيد: راجع الموسوعاة الفقهية،

:124-123/37

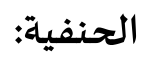
1. ما كان من عمل قبل إدراك الثمر من السقي والتلقيح والحفظ، فهو على العامل، وما بعد الإدراك كالجذاذ، وحفظه فهو عليهما. 2. ما لا تبقى منفعتـه بعد مدة العقد فهو على العامل، فاشتراطه عليه لا يفسد العقد، وما تبقى منفعتاه بعدها كفرس الأشجار، فاشتراطه على العامل يفسـد العقد. المالكية: 1. لا يشترط تفصيل العمل، ويحمل على العرف إن كان منضبطًا، وإلا فلا بد من البيان. 2. ما لا يتعلق بالثمرة ولا تأثير لله في صلاحها لا يلزم العامل بالعقد، ولا يجوز أن يشترط عليه إلا اليسير منـه. 3. ما يتعلق بالثمرة ويبقى بعدها أو يتأبد، كحفر بئر،

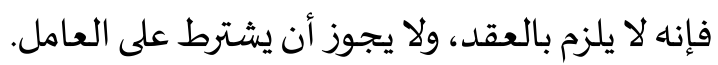
4. ما يتعلق بالثمرة ولا يبقى أو لا يتأبد فهو واجب على

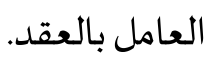
الحنابلة: - (الح 1. يلزم العامل ما فيه صلاح الثمرة وزيادتها مثل

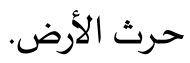


إلى عرف أهل المهنة.فما هو معتاد أن يتحمله أحد العاقدين في هذا النوع من النشاط يلزَمُهـ تحمّلُه.

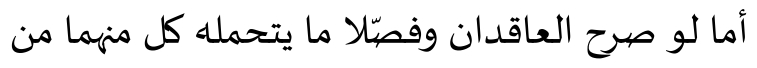
تكاليف، فلا تكاد توجد صورة إلا ومن الفقهاء من يجيزها كما رأينا في المزارعة وسواها. وهذا يتيح مرونة كاملة لابتكار الإنا صيغ تلائم المتطلبات المتنوعة لأطراف العقد، ليختار كلو تلك البنود من التكاليف التي تلائم وضعه المالي ودرجة ميله أو كراهته للخطر. حيث إن المدخلات اللازمة تختلف في تكاليفها وفي أنواع المخاطر التي يتحملها من التزم بتقديمها.
• • عدم جواز إلزام طرف بتقديم مدخلات رأسمالية تبقى لها منافع ينفرد بها الطرف الآخر بعد انتهاء العقد.

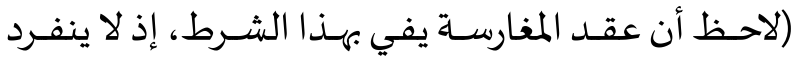

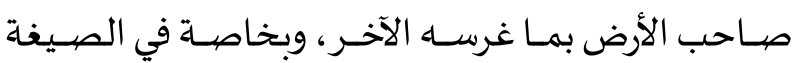

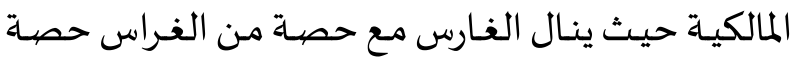

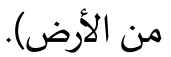

ثم إن سكت العاقدان عن التفصيل، فقد اختلف الفقهاء فيما يرون أنه الأصل الفقهي الذي يردّ إليه العاقدان إن وقع بينهما خلاف. والغالب فقهيًا أن يردّا شكل (2): تقسيم الشافعية للأعمال التي تجب على المساقي ورب الشجر

\section{نوع العمل في المساقاة}

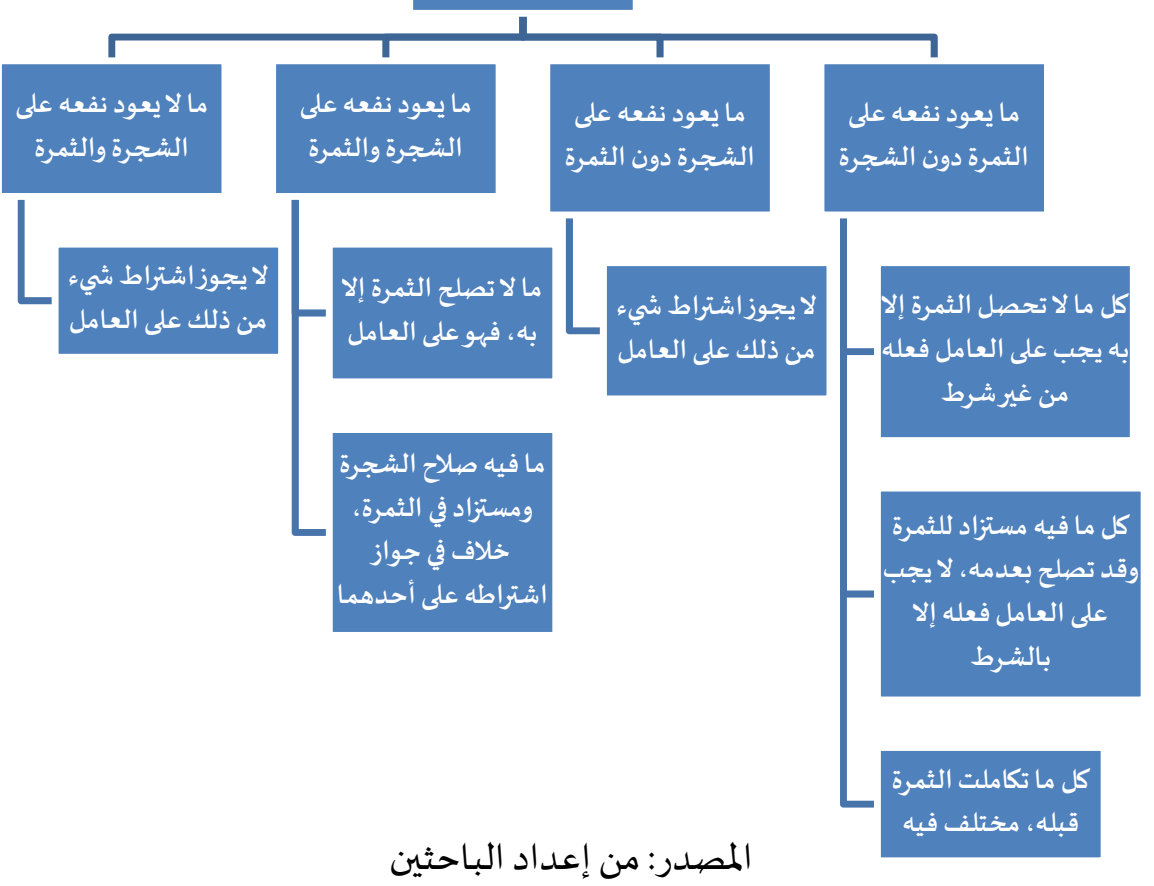

للاستثمار (مثل الأرض) ويرغب في استثماره من خلال

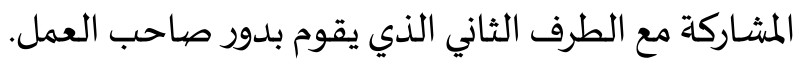

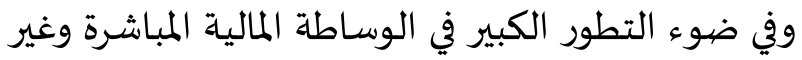
المباشرة يمكن تصور دخول المؤسسات المالية طرفًا
5- نموذج مقترح للمشاركة التفضيلية في الإيراد: 1-5 الإمكانات الواعدة لصكوك المشـاركة في الإيراد عقود المشاركة في الإيراد يمكن أن تطبق بالاتفاق المباشر بين طرفين: الأول يملك أصلاً إنتاجيًا قابلاً 
2. تقلل المشاركة في الإيراد من مخاطر تفاوت المعلومات بين الطرفين؛ لأن المشاركة تقع على الإيراد (المبيعات أو الناتج) وهو قابل غالبًا للمشاهدة ويصعب المان التلاعب فيه مقارنًا بالريح الذي يدخل في تحديد الندال كثيرة بعضها خفي تصعب مراقبته. ولهذا فإن المخاطر

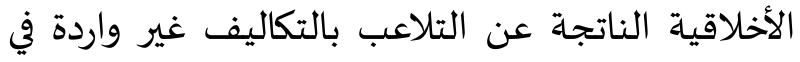
حالة المشاركة في الإيراد، لأن صاحب الأرض لن يكون بحاجة لمراقبة التكاليف مطلقًا. 3. لا يتحمل الممول التكاليف المتعلقة برأس المال الثابت للمشروع كالإهلاك. وهذا يعني أن الإيرادات التي

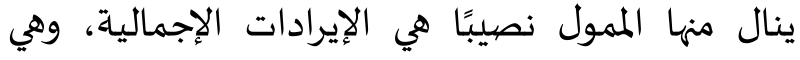

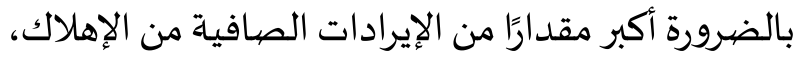
وأبعد عن احتمال أن تصبح سالبة. وتزداد قيمة هذه الميزة

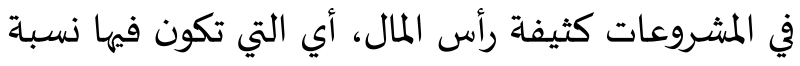
رأس المال إلى الناتج مرتفعة مثل كثير من مشروعات البنية

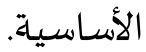

4. إن مما يقلل من مخاطر التمويل بصيغة المشاركة

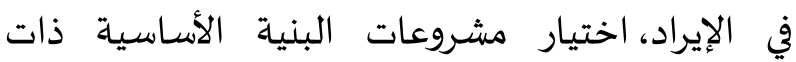
الإيرادات المستقرة نسبيًا (أي قليلة التقلب، كتزويد المدن بالكهرباء مثلاً) التي يسهل توقع إيراداتها بدقة ومراقبتها

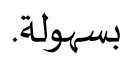
5. إن أي طرف يقدم تمويلاً في عقد مشاركة في الإيراد

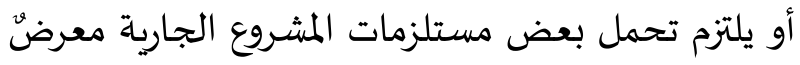
لاحتما ل خسارة محاسبية إذا لم تبلغ حصته من الإيرادات المتحققة ما يغطي نفقاته. لكن قوى السوق كفيلة بتصحيح ذلك في الأجل المتوسط، إذ لن يرضى الطرف

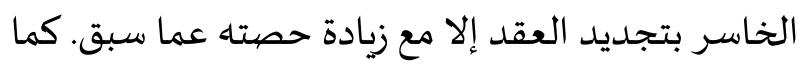
يمكن توقي ذلك إذا جُعلت مدة العقد الأول قصيرة نسبيًا،
وسيطًا يمول أحد الطرفين أو كليهما. وفي هذه الحالة يتعاقد الوسيط بدوره مع طرف ثالث ليقوم بالدور

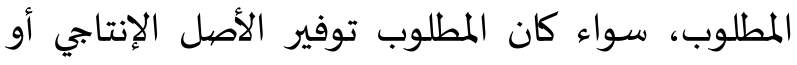
القيام بالعمل الإنتاجي. ويتم الاتفاق بين الوسيط والطرف التان

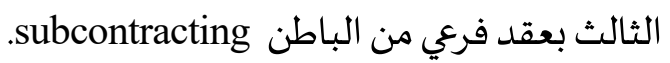
وعلى الرغم من اشتمال معيار صكوك الاستثمار (المعيار

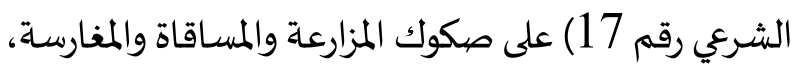
إلا أهنا لم تطبق حتى الآن في الأسواق المالية الإسلامية فيما

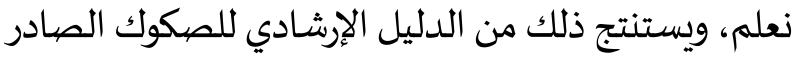

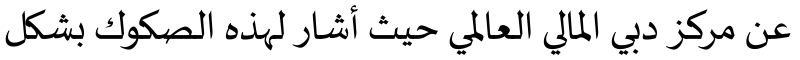
مقتضب تحت عنوان "هياكل أخرى" ولم يشر إلى أهنا طبقت على أرض الواقع (DIFC, 2009: 64-65). إن هذه الصكوك من وجهة نظرنا مرجوة جدًا للتطبيق إذا تم تطويرها بما يوافق الشريعة ويتلاءم مع حاجة الثداه الحكومات لإنشاء مشروعات البنية الأساسية وتشغيلها، ويتلاءم أيضًا مع متطلبات المستثمرين وشركات المقاولة المنفذة لهذه المشروعات على أرض الواقع. وقد أكد الزرقا (Zarqa, 2016: 9) على الدور الكامن

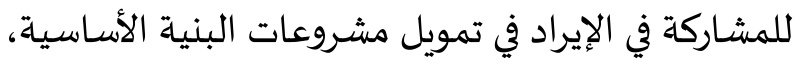
منطلقًا من المساقاة كمثال لهذه المشاركة، مشيرًا إلى عدد

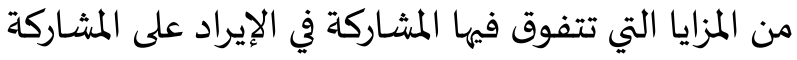

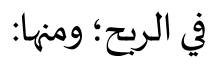
1. إن المشاركة في الإيراد تحصن الممول من المخاطر

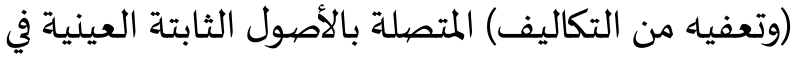

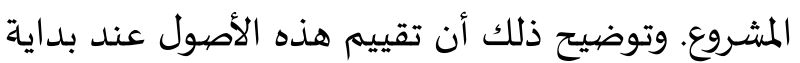

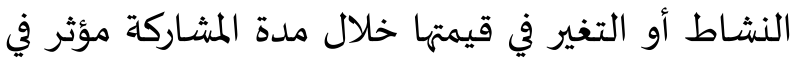
الريح في عقود المشاركة في الريح كالمضاربة، وغير مؤثر في الإيراد في عقود المشاركة في الإيراد كالمساقاة. 
المراقبة؛؛ حيث أن التخلية التامة لصاحب العمل قد يغريه باتخاذ بعض التصرفات التي تزيد التكاليف أو تعظم

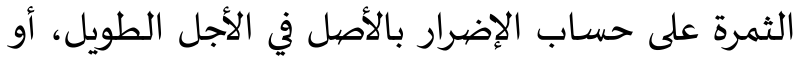
بجودة الثمرة في الأجل القصير (مثل الغش باستخدام الأسمدة الكيماوية بنسب أعلى من المسموح بها). 4. يضاف لمزايا الشراكة في الإيراد التي أشار إليها الزرقا أن الأصل الإنتاجي وهو الأرض يظل مملوكًا للحكومة خلال مدة تنفيذ المشروع، لأن الشركة تنتفع باه ولا تملكاه، وهذا يجنب الحكومة الدخول في إشكالات بيع أصولها السيادية التي تحصل في هياكل كثير من الصكوك السيادية، وتبعا لذلك لن يتمكن دائنو صكوك المشاركة في الإيراد - في حال وجودهم - من النفاذ لهذا الأصل في حال الخسارة أو إعلان الإفلاس.

علاوة على ما سبق، يمكن تعزيز هياكل الصكوك القائمة على المشاركة في الإيراد ببعض الابتكارات التي تقلل

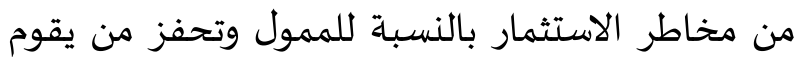
فعلاً بدور العامل. ومن ذلك تطبيق فكرة الأسههم التفضيلية الإسلامية على هذه الصكوك (بحيث يُفضَّل الممول (وهم حملة الصكوك) في الحصول على إيراد أعلى اهلى الصهيل على حساب مالك الأرض، أو تحمل مالك الأرض تكلفة أعلى لحين تحقق معدل عائد مستهدف لحملة الصكوك، ثم تتغير النسبة بعد ذلك لصالح مالك الأرض. والوظيفة الاقتصادية التي يحققها هذا التفضيل هي أنها يسمح بأن يُجتذب للمشروع نفساه ممولين ذوي توقعات مختلفة عن درجة نجاح المشروع، وذوي متطلبات مختلفة عن درجة الخطر التي يرضون بتحملها. وقد فُصل ذلك في بحث (الزرقا والسحيباني، 2012).
بحيث تتضح خلالها الإيرادات والتكاليف الفعلية، مما يسمح للطرفين المتعاقدين بعقد جديد لفترة قادمة مبني على تصحيح التوقعات السابقة إذا انكشف عدم واقعيتها. وإذا ما أدخلنا المغارسة ضيمن نماذج عقود المشاركة في الإيراد، وأخذنا في الاعتبار الاجتهادات التي قدمها الفقهاء حول تفاصيل تنفيذ هذه العقود، فسيكون هناك مزيد من الخيارات المتاحة لتطبيق عقود المشاركة في الإيراد في تمويل مشروعات البنية الأساسية. ومن ذلك ما يلي: 1. تتطلب المغارسة - خلافًا للمزارعة والمساقاة استثمارًا رأسماليًا (إنشاء أصل قابل للإنتاج) ولهذا فهي تحتاج إلى تمويل رأسمالي أكبر، وتتناسب أكثر مع صيغ المشاركة بين القطاعين العام والخاص التي يلتزم فيها القطاع الخاص بإنشاء مرافق البنية الأساسية. 2. يستحق المغارس- خلافًا للمزارع والمساقي - جزءًا من الأرض والغرس حسب رأي المالكية، وهو ما يجعله مشاركًا لرب الأرض في تحمل مخاطر تملك الأصيول الثابتة والعينية. في المقابل، قصر الحنفية والحنابلة جواز المغارسـة على الشركة في الغرس أو الثمرة فقط (الموسوعة

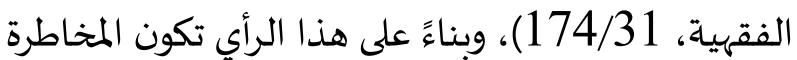
أقل؛ لأن الأصيول التي يملكها المغارس سوف تنحصر في بعض الأصيول الثابتة. 3. كما أشرنا في القسم الرابع، تتمتع عقود المشاركة في الإيراد بمرونة فيما يتعلق بآلية تقاسم تكاليف الإنتاج. وعلياء، يمكن الاتفاق مع تقاسم الناتج على تحمل رب الأرض بعض بنود التكاليف المتغيرة بالإضافة إلى تقديم الأرض. ولا شك أن مشاركة رب الأرض في تحمل تكلفة بعض المدخلات (مثل السقي أو نحوها) وليس نسبة مشاعاة من التكاليف، هي مما يساعد في تقليل تكلفة 
والعلاقة الثانية الفرعية بين شركة التمويل والشركة المنفذة. وسنركز في البداية على العلاقة التعاقدية الأولى،

ثم نتطرق في نهاية هذا القسم للعلاقة التعاقدية الثانية. 3-5 المشاركة في الإيراد بين الطرفين الأول والثاني نفترض أن الإيراد الكلي من المشروع (R) سيتوزع الإيران الطرفين

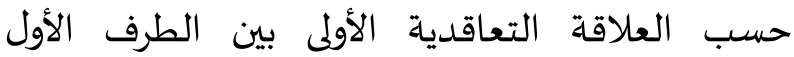
(الحكومة) والطرف الثاني (شركة التمويل) كالآتي:

$$
\begin{aligned}
& \mathrm{R}=\mathrm{R}_{1}+\mathrm{R}_{2} \\
& \mathrm{R}_{1}=\mathrm{a} \mathrm{R} \\
& \mathrm{R}_{2}=(1-\mathrm{a}) \mathrm{R}
\end{aligned}
$$

حيث تمثل "a" نسبة ما يذهب من الإيراد الكلي

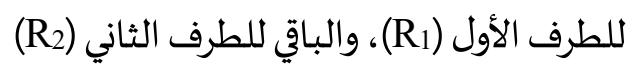

1-3-5 الحالة الأولى: نسبة مشاركة ثابتة في الإيراد في هذه الحالة يفترض أن تكون نسبة المشاركة (a) ثابتة للطرفين بغض النظر عن أي متغيرات أخرى، وتحدد النسبة بناء على التفاوض بينهما، أخذًا في الاعتبار الأعمال ونسبة التكلفة التي سيتحملها كل طرف. وكما أشرنا أعلاه كلما ارتفعت التكلفة التي يتحملها أي طرف فمن المتوقع أن أن الميات يطالب بنسبة مشاركة أعلى لتحقيق ربحه المستهدف. وإذا كان المشروع برمته مجديًا اقتصاديًا وقابلاً للتمويل فسيجد الشركاء بالتفاوض آلية لتوزيع المخاطر والعائد بما

$$
\text { يضمن توافق مصالح الجميع. }
$$

ويوضح الشكل (3) إيراد الطرفين بافتراض أن نسبة

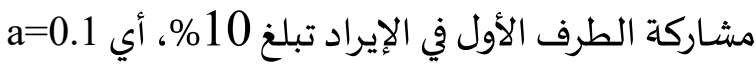

وتبين الفقرات الآتية طريقة تطبيق هذه التفضيلات على الصكوك القائمة على المشاركة في الإيراد. 2-5 الأطراف والعلاقات التعاقدية الأساسية: لتبسيط العرض والتحليل في الفقرات الآتية نفترض وجود ثلاثة أطراف رئيسة في صكوك المشاركة في الإيراد،

1. الحكومة التي تملك الأراضي التي ستقام عليها مرافق البنية الأساسية، وترغب في الحصول على تمويل لإنشائها وتشغيلها، فهي المنشئ للصكوك والمتمول الرئيس في صفقة التصكيك.

2. شركة تمثل حملة الصكوك، وتتولى إصدار

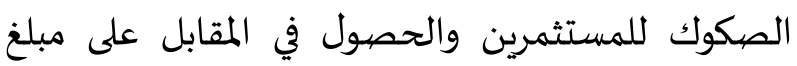
الاكتتاب، لتقوم بعد ذلك بحفظ أصول المستثمرين والتعاقد نيابة عنهم مع جميع الأطراف الأخرى ذات العلاقة حسب هيكل الصك، فهذه الشركة هي الممول المصددر للصكوك، وسيتم تسميتها: شركة التمويل. 3. شركة متخصصية في تنفيذ مرافق مشروع البنية الأساسية وتشغيلها، وهي شركة مستقلة تتولى إنشاء وتشغيل مرفق البنية الأساسية من خلال التعاقد مع مقاولين للتوريد والبناء والإدارة حسب التقدم في تنفيذ التئ المشروع، وسيتم تسميتها: الشركة المنفذة. وسيكون هناك علاقتان تعاقديتان في هذا الصك: العلاقة الأولى والأساسية بين الحكومة وشركة التمويل، 
(1) التنازل عن جميع الإيراد الفعلي (R) لشركة

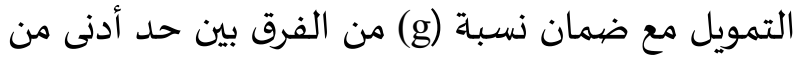

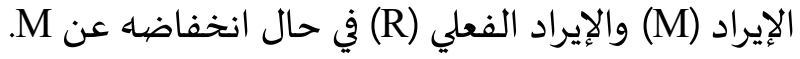

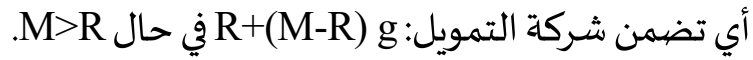
(2) منح جميع الإيراد لشركة التمويل فوق الحد (X) إلى أن يصل الإيراد إلى قيمة عليا (X). (3) يتم تقاسم الإيراد بين الطرفين بعد هذه القيمة العليا؛ بحيث تحصل الحكومة على نسبة (h). ويتم تحديد قيم المعلمات (M, g, h) بناء على التفاوض بين الطرفين. ويوضح الجدول (1) المعادلات التي يتم بموجبها حساب إيراد كل طرف خلال المراحل الثلاث التي يمر بها الإيراد الكلي.
2-3-5 الحالة الثانية: نسبة مشاركة متغيرة في الإيراد (مع ضهمان حد أدنى)

نفترض في هذه الحالة أن نسبة المشاركة في الإيراد (a) تتغير مع ضمان الحكومة لحد أدنى من الإيراد؛ بهدف تحقيق توزيع أمثل للمخاطر بين الأطراف، وتحفيز القطاع الخاص لتحقيق أكبر منفعة من الاستثمار في المشروع.

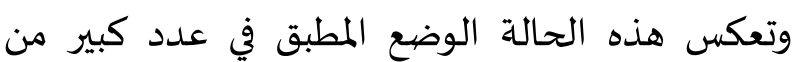
مشروعات الشراكة بين القطاعين العام والخاص؛ حيث تسعى الحكومة (الطرف الأول) لتخفيف مخاطر شركة التمويل (الطرف الثاني) بطرق متنوعة بعضها غير جائز فقها كما سنرى لاحقًا. من تلك الطرق:

جدول (1): مراحل التغيرفي نسبة المشـاركة في الإيراد

\begin{tabular}{|c|c|c|c|c|}
\hline نسبة شركة التمويل من الإيراد، *a-a & إيراد شركة التمويل، & الحكبة مشـاركة & الحكومة، إيراد & الإيراد الفعلي، R \\
\hline 1 & $\mathrm{R}+(\mathrm{M}-\mathrm{R}) \mathrm{g}$ & 0 & - (M-R)g & $\mathrm{R}<\mathrm{M}$ \\
\hline 1 & $\mathrm{R}$ & 0 & 0 & $\mathrm{X}>\mathrm{R}>\mathrm{M}$ \\
\hline $1-\mathrm{h}$ & $\mathrm{X}+(\mathrm{R}-\mathrm{X})(1-\mathrm{h})$ & $\mathrm{h}$ & $(\mathrm{R}-\mathrm{X}) \mathrm{h}$ & $\mathrm{R} \geq \mathrm{X}$ \\
\hline
\end{tabular}

المصيدر: من إعداد الباحثين

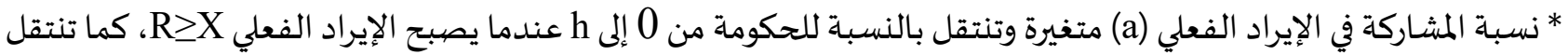

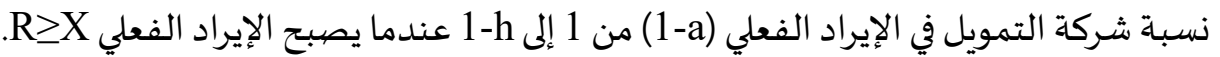


والسحيباني، 2012)، نفترض هنا أن معدل المشاركة

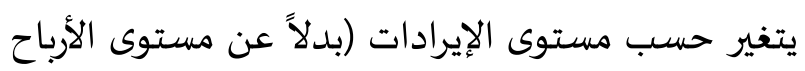

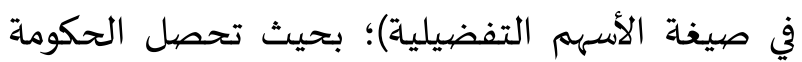

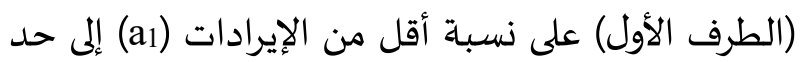
معين (M) ) لترتفع بعده هذه النسبة إلى (a2)، ثم ترتفع إلى الإني

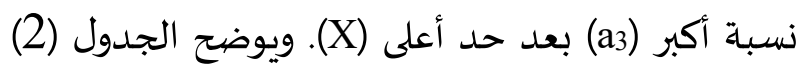

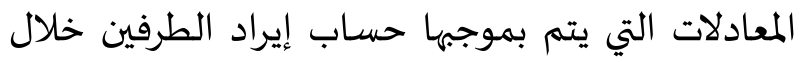
المماحل الثلاث التي يمر بها الإيراد الكلي.
ويرسم الشكل (4) إيراد الطرفين بافتراض القيم

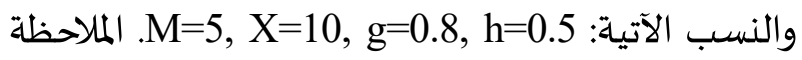

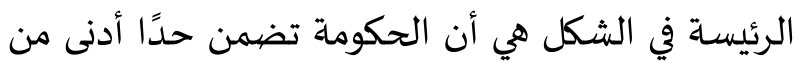

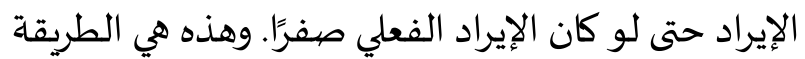
المتبعة في بعض مشروعات الشراكة بين القطاعين العام الئرام والخاص، وقد يؤدي هذا الضمان إلى عائد مضمون لصكوك الإيراد، مما يؤثر على سلامتها الشرعية. 3-3-5 الحالة الثالثة: الصكوك التفضيلية كما هو الحال بالنسبة للأسهم التفضيلية (الزرقا

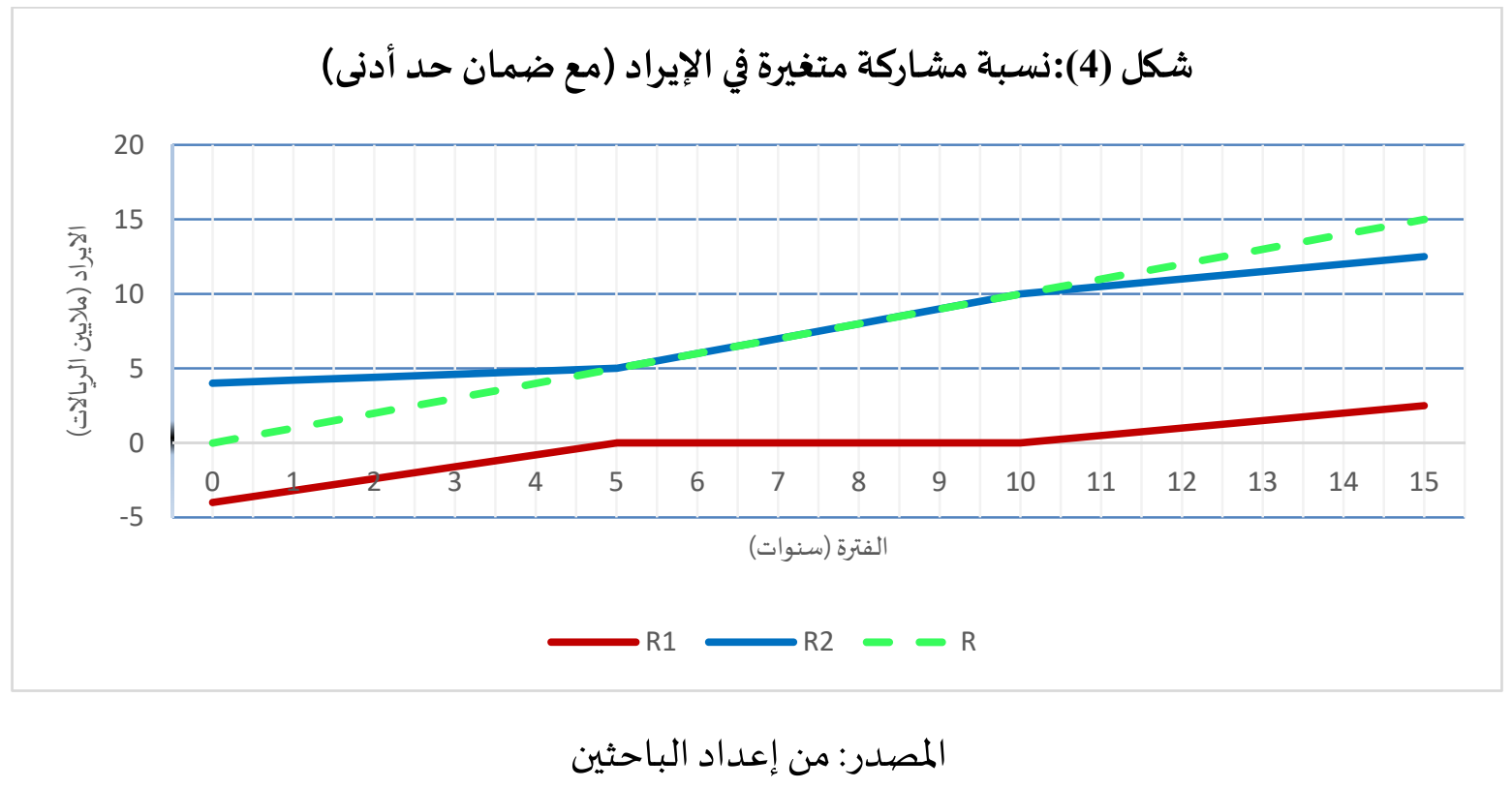

جدول (2): مراحل التغيرفي نسبة المشاركة في إيراد الصكوك التفضيلية

\begin{tabular}{|c|c|c|c|c|}
\hline نسبة شركة الإيراد الإضمافيل & إيراد شركة التمويل، R2 & 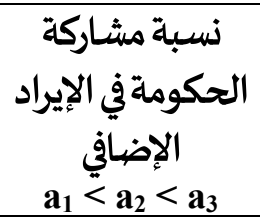 & إيراد الحكومة،، R & الإيراد، R \\
\hline$\left(1-a_{1}\right)$ & $\left(1-a_{1}\right) R$ & $a_{1}$ & $\mathrm{a}_{1} \mathrm{R}$ & $\mathrm{R}<\mathrm{M}$ \\
\hline$\left(1-a_{2}\right)$ & $M\left(1-a_{1}\right)+(R-M)\left(1-a_{2}\right)$ & $\mathrm{a}_{2}$ & $\mathrm{Ma}_{1}+(\mathrm{R}-\mathrm{M}) \mathrm{a}_{2}$ & $\mathrm{X}>\mathrm{R}>\mathrm{M}$ \\
\hline$\left(1-a_{3}\right)$ & $\begin{array}{c}\mathrm{M}\left(1-\mathrm{a}_{1}\right)+(\mathrm{X}-\mathrm{M})\left(1-\mathrm{a}_{2}\right)+(\mathrm{R}- \\
\mathrm{X})\left(1-\mathrm{a}_{3}\right)\end{array}$ & $a_{3}$ & $\begin{array}{c}\mathrm{Ma}_{1}+(\mathrm{X}-\mathrm{M}) \mathrm{a}_{2}+(\mathrm{R}- \\
\mathrm{X}) \mathrm{a}_{2}\end{array}$ & $\mathrm{R}>\mathrm{X}$ \\
\hline
\end{tabular}

ويرسم الشكل (5) إيراد الطرفين بافتراض القيم والنسب الآتية: M=5, X=10, a = =0.05, a2=0.5, a3 =0.8 


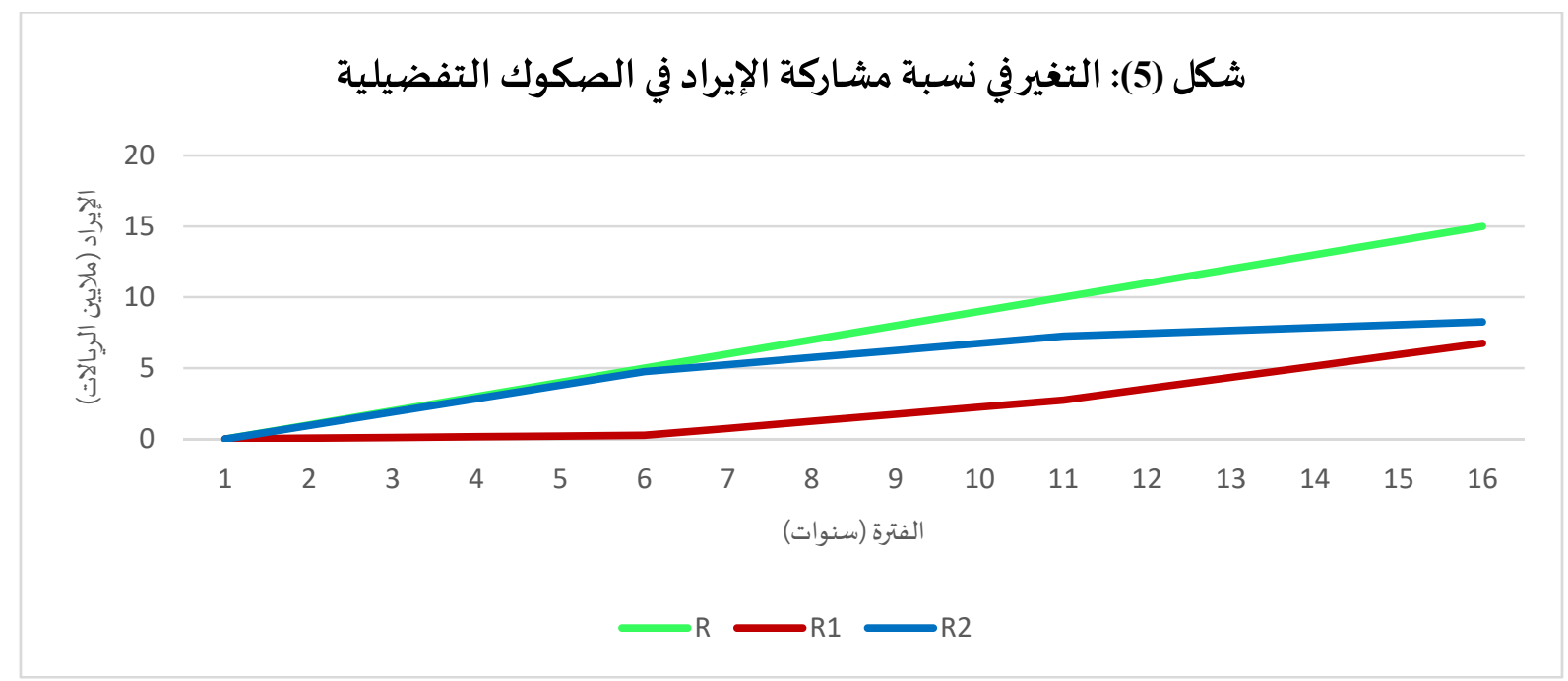

المصيدر: من إعداد الباحثين

ولتحقيق هذا الهدف نفترض - كما هو الحال في

الإيراد - اشتراك الطرفين في التكاليف الكلية للمشروع (C)

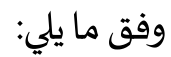

$$
\begin{aligned}
& \mathrm{C}=\mathrm{C}_{1}+\mathrm{C}_{2} \\
& \mathrm{C}_{1}=\mathrm{d} \mathrm{C} \\
& \mathrm{C}_{2}=(1-\mathrm{d}) \mathrm{C}
\end{aligned}
$$

حيث تمثل d نسبة ما يتحمله الطرف الأول من التكاليف (C) أن استخدامنا للنسبة (d) هو لغرض تبسيط التحليل،

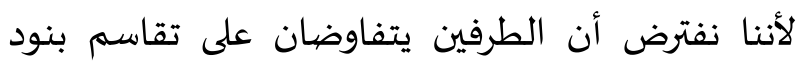

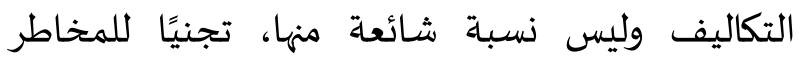
الأخلاقية التي تمت الإشارة إليها أعلاه. وبناء عليه سيتم

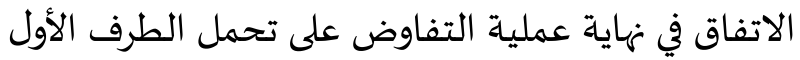
عددًا من بنود التكاليف في حين يتحمل بقية البنود الطرف الطيه الآخر. وبالتالي فإن النسبة (d) تمثل حصة مان ما تحمله الطرف الأول من بنود التكاليف وليس نسبة شائعة من

$$
\text { إجمالي التكاليف. }
$$

ولو انطلقنا من فرضية تساوي نسبة تحمل التكاليف

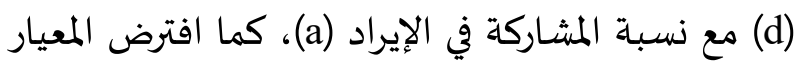

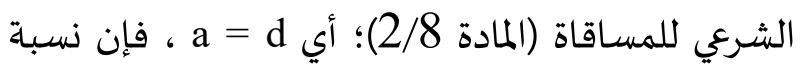

$$
\begin{aligned}
& \text { ويتضح من الشكلين (4) و (5) أن الفروق الرئيسة بين } \\
& \text { الحالتين الثانية والثالثة هي: }
\end{aligned}
$$

1. لا يوجد ضمان حد أدنى من الإيراد في الحالة الثالثة مقارنة بالثانية، حيث إن إيراد الطرف الثان الثاني أقل الثل

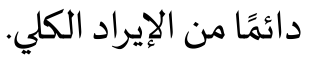
2. لا تنقطع المشاركة في الحالة الثالثة؛ حيث يتشارك الطرفان في الإيرادات في جميع مراحل التغير في الإيراد

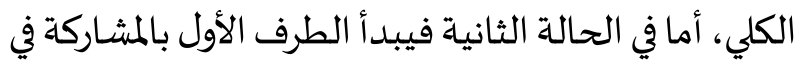
الإيراد بعد بلوغ الإيراد الحد الأعلى (X).

4-3-5 الحالة الر ابعة: تأثير المشـاركة في التكاليف

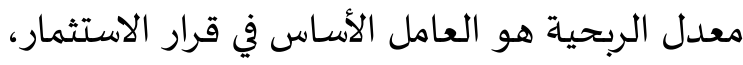

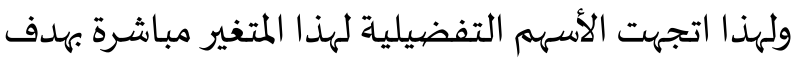
التأثير على قرارات الاستثمار والتمويل. وبالمنطق نفسهاه، تتأثر قرارات جميع الأطراف في عقود المشاركة في الإيراد بمعدل الربحية لكل طرف على الرغم من كونه خارج

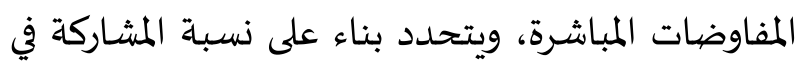
الإيراد والتكاليف التي يتم التفاوض والاتفاق عليها. وعليه،

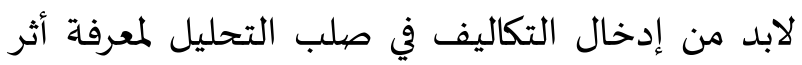
التفضيل في الإيراد على الربح. 
المنفذة). ويمكن أن يتم التعاقد بعدة صيغ منها الإجارة أو الاستصناع. ونفترض أهها ستكون بصيغة المشاركة في الماني

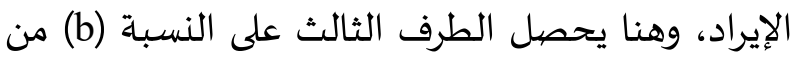
إيراد الطرف الثاني في العلاقة التعاقدية الأساسية والبالغ:

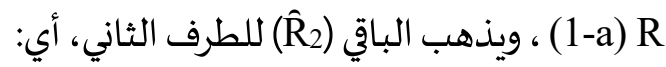

$$
\mathrm{R}_{3}=\mathrm{b} \mathrm{R}_{2}=\mathrm{b}(1-\mathrm{a}) \mathrm{R}
$$$$
\hat{\mathrm{R}}_{2}=(1-\mathrm{b}) \mathrm{R}_{2}=(1-\mathrm{b})(1-\mathrm{a}) \mathrm{R}
$$

حيث يصبح ما يذهب للطرف الثالث من الإيراد الكلي

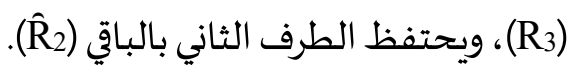

وبمنطق تقاسم التكاليف أعلاه، يتقاسم الطرف الثاني

التكاليف مع الطرف الثالث بنسبة مختلفة، فيتحمل

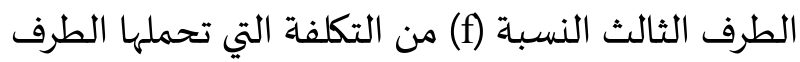
الثاني بموجب العلاقة التعاقدية الأساسية البالغة: (d-1)

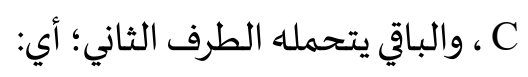

$\mathrm{C}_{3}=\mathrm{fC}_{2}=\mathrm{f}(1-\mathrm{d}) \mathrm{C}$

$\hat{\mathrm{C}}_{2}=(1-\mathrm{f}) \mathrm{C}_{2}=(1-\mathrm{f})(1-\mathrm{d}) \mathrm{C}$

حيث يصبح ما يتحمله الطرف الثالث من التكاليف (C2)، ويتحمل الباقي الطرف الثاني (C)

ويمكن تلخيص المعادلات السابقة التي تبين طريقة

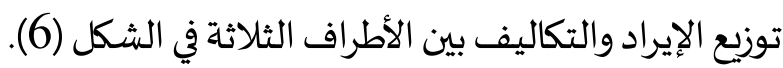

مشاركة كل طرف في الإيراد تصبح هذه الحالة مساوية لنسبة مشاركته في الريح (Y)، أي تنقلب المشاركة في الإيراد لمشاركة في الريح. حيث يساوي ريح الطرف الأول:

$$
\mathrm{Y}_{1}=\mathrm{R}_{1}-\mathrm{C}_{1}=\mathrm{a} \mathrm{R}-\mathrm{dC}
$$

فإذا كانت نسبة المشاركة في الإيراد مساوية لنسبة

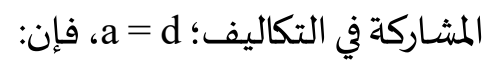

$$
\hat{\mathrm{Y}}_{1}=\mathrm{a} \mathrm{R}-\mathrm{aC}=\mathrm{a}(\mathrm{R}-\mathrm{C})=\mathrm{a} \mathrm{Y}
$$

$$
\text { حيث تساوي Y مجموع ربح الطرفين: }
$$

$$
\begin{aligned}
\mathrm{Y}=\mathrm{Y}_{1}+\mathrm{Y}_{2} & =\mathrm{R}_{1}-\mathrm{C}_{1}+\left(\mathrm{R}_{2}-\mathrm{C}_{2}\right)=\mathrm{R}-\mathrm{C}(9) \\
& \text { وبالمثل بالنسبة لريح الطرف الثانية }
\end{aligned}
$$$$
\hat{\mathrm{Y}}_{2}=\mathrm{R}_{2}-\mathrm{C}_{2}=(1-\mathrm{a}) \mathrm{R}-(1-\mathrm{d}) \mathrm{C}=(1-\mathrm{a}) \mathrm{Y} \quad \text { (10) }
$$

وبناء عليه، إذا اتفق الطرفان على الاشتراك في تحمل

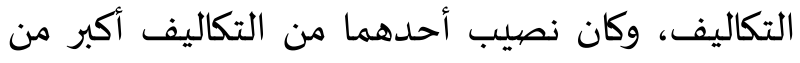

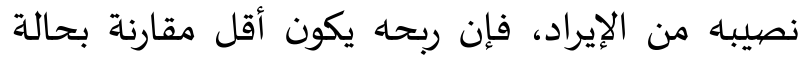
تساوي حصته من التكاليف مع حصيته من الإيراد. أي إذا لإنا

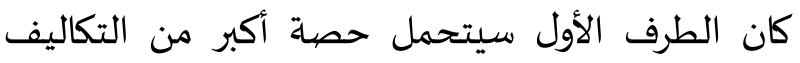

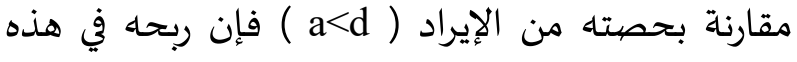
الحالة، Y1، سيكون أقل مقارنة بالريح في حال تساوي

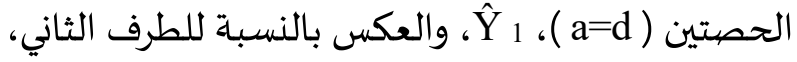

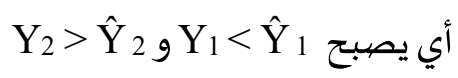
4-5 المشاركة في الإيراد بين الطرفين الثاني والثالث: كما أشرنا أعلاه، يوجد علاقة ثانية فرعية يتعاقد فيها الطرف الثاني (شركة التمويل) مع الطرف الثالث (الشركة

\section{شكل (6): توزيع الإيراد والتكاليف بين الأطراف الثلاثة في الصكوك التفضيلية}




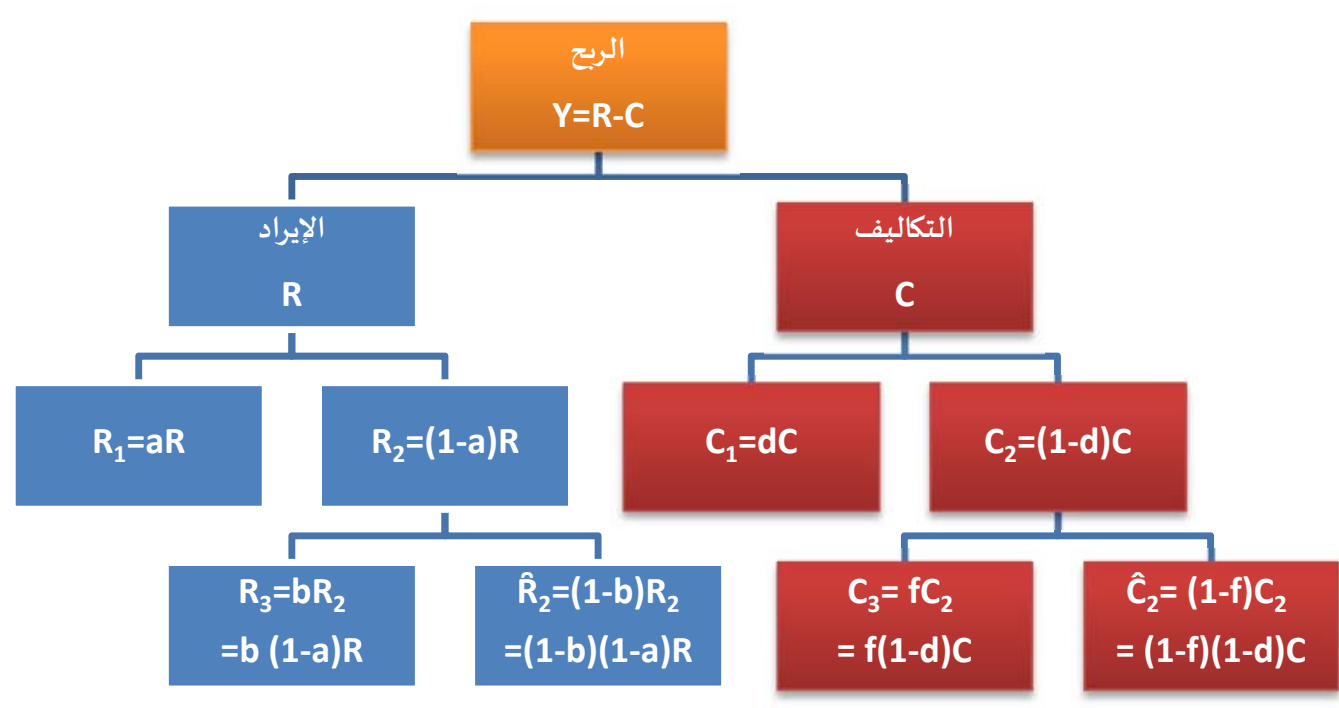

المصدر: من إعداد الباحثين

(b-k) $\mathrm{R}_{2}=-\mathrm{kC}_{2}$

$\mathrm{R}^{*}{ }_{2}=\mathrm{kC}_{2} /(\mathrm{k}-\mathrm{b})$

فإذا كان الإيراد الكلي أقل من R*2 تحصل الشركة

المنفذة على bR2 ، وإذا كان أكبر من 2R 2 تحصل الشركة

المنفذة على الإيراد الأعلى kY2، وتبعًا لذلك ترتفع النسبة المبا

الفعلية التي تحصل عليها الشركة من الإيراد من bإلى إلى:

$\mathrm{b}^{\prime}=\mathrm{kY}_{2} / \mathrm{R}_{2}=\mathrm{k}\left(\mathrm{R}_{2}-\mathrm{C}_{2}\right) / \mathrm{R}_{2}=\mathrm{k}-\left(\mathrm{kC}_{2} / \mathrm{R}_{2}\right)$

وهنا نلاحظ أن فرصة الشركة المنفذة في الحصيول على

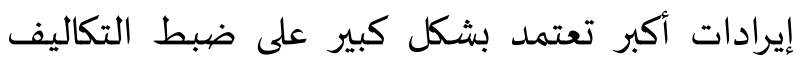

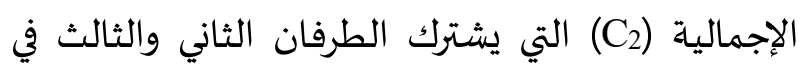
تحملها، حيث إن نقطة التحول لإيراد أعلى (R

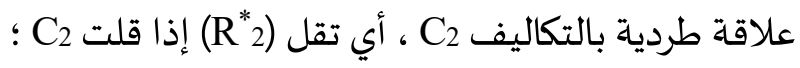

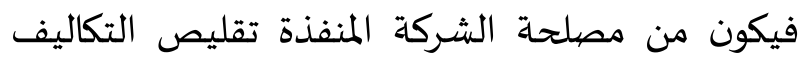

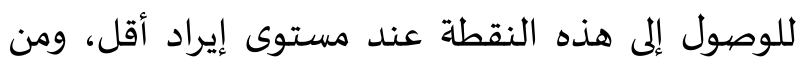

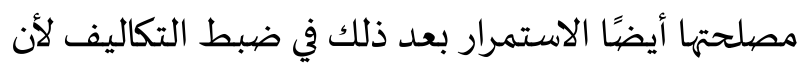
نسبتها من الإيراد تتزايد بسبب ذلك، حيث إنبا إن العلاقة بين b' والتكاليف الكلية C2
وخلافًا للهدف من المعاملة التفضيلية في العلاقة التعاقدية الأسـاسية، والتي ركزت على تخفيض مخاطرافر المعامله استثمار الطرف الثاني، تركز المعاملة التفضيلية في هذه التهائه

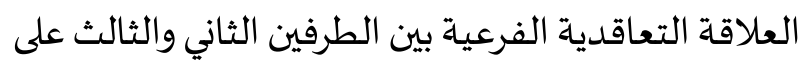
تحفيز الأخير (الشركة المنفذة) للتنفيذ بأعلى كفاءة ممكنة. وتتمثل المعاملة التفضيلية للطرف الثالث في هذه الميره

$$
\hat{\mathrm{R}}_{3}=\operatorname{Max}\left\{\mathrm{bR}_{2}, \mathrm{kY}_{2}\right\}
$$

وتعني أن الشركة المنفذة ستحصل على القيمة الأكبر من (1) نصيبها من الإيراد المتفق عليه في العقد أو (2)

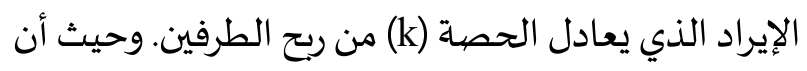
الإيراد عادة أكبر من الربح، فيشترط تبعًا لذلك أن تكون: k>b

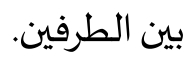

ويمكن معرفة مستوى الإيراد الذي تبدأ عنده الشركة المنفذة في الحصول على نسبة أعلى من الإيرادات بحل هذه المعادلة: $\mathrm{b} \mathrm{R}_{2}=\mathrm{k} \mathrm{Y}_{2}=\mathrm{k}\left(\mathrm{R}_{2}-\mathrm{C}_{2}\right)=\mathrm{kR}_{2}-\mathrm{kC}_{2}$ 


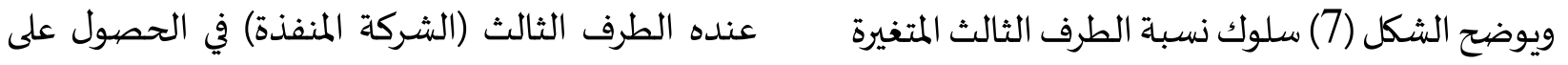
من الإيراد 'bافتراض مبسط وهو تمكّن هذا الطرف من نسبة أعلى من الإيرادات هو:

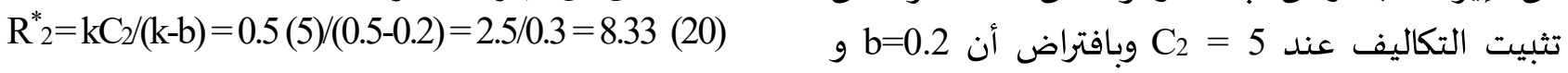
k=0.5. ويلحظ من الشكل أن مستوى الإيراد الذي بدأ

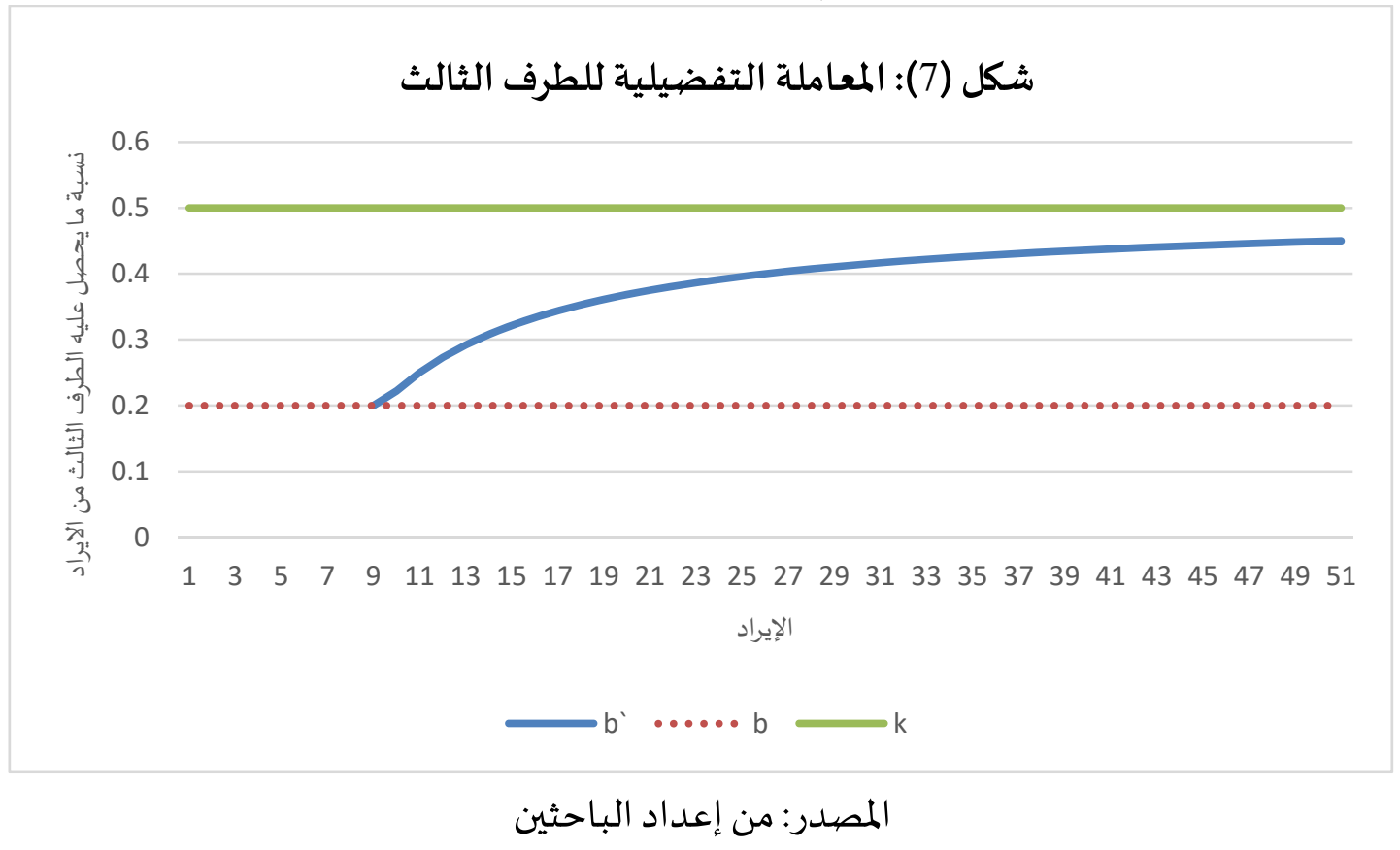


6- تحليل ومناقشـة:

الثاني؛ من خلال زيادة احتمال حصوله على ربح أعلى أو خسارة أقل، ويزيد في الوقت نفساه من احتمال دفع الحكومة لهذه المطلوبات المحتملة في المستقبل. وهنا يبرز

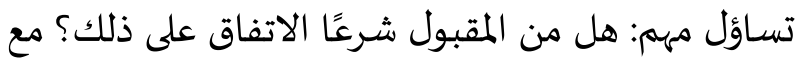

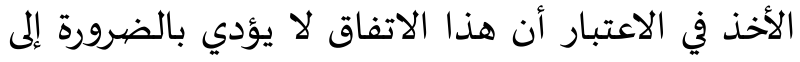

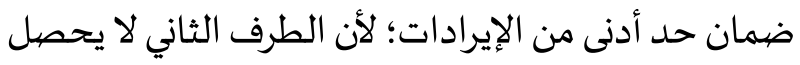
إلا على نسبة أعلى من الإيراد مشروطة بتحقق إيراد فعلي. وتبعا لذلك، لا يحصل الطرف الثاني على شيء لو كان

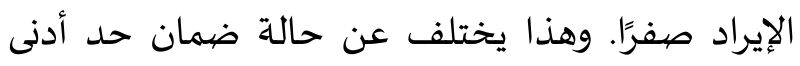
بغض النظر عن مستوى الإيراد الفعلي (الحالة الثانية في الفقرة 6-3-2)، والتي يمكن أن يحصل فيها الطرف الثاني على نسبة (90\%) من الحد الأدنى Mتى لو كان الإيراد

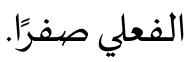

اقترحنا في الحالة الرابعة (الفقرة 6-3-4) أن يتفاوض الطرفان على تقاسم بنود التكاليف وليس نسبة شائعة منها، تجنبًا للمخاطر الأخلاقية. ومن الاعتراضات التي

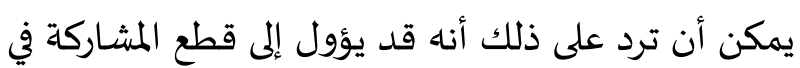

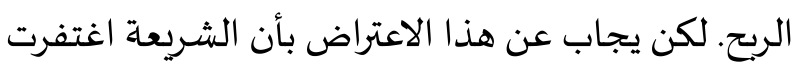
ذلك حين أباحت المساقاة، وهي الحالة القصوى التي يتحمل أحد الطرفين (المساقي) فيها كامل تكاليف التشغيل،

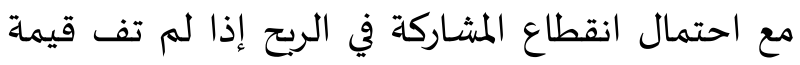

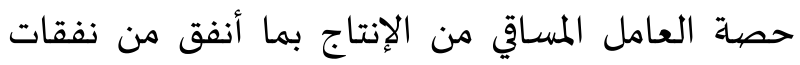

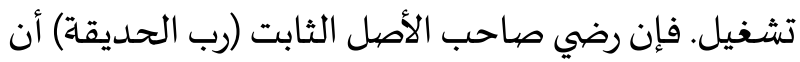

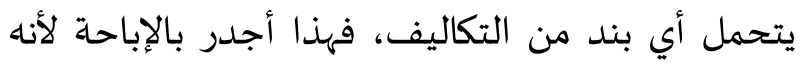
يقلل احتمال قطع المشاركة.

إن منع اشتراط ما قد يؤدي إلى قطع المشاركة هو مبدأ

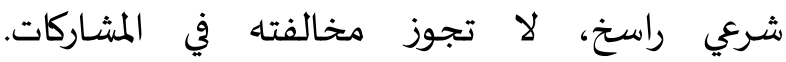
لكن الشريعة السمحة أرشدتنا إلى أسلوب وسط فئ في
تدل النتائج التي تم التوصل إلهها في الأقسام السابقة

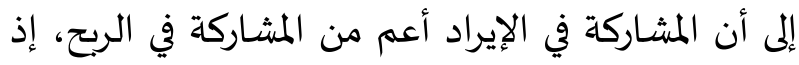

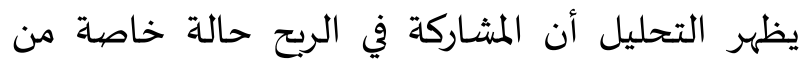
المشاركة في الإيراد في حال تساوي نسبة المشاركة في الإيراد مع نسبة المشاركة في التكاليف. وأن المشاركة في الإيراد

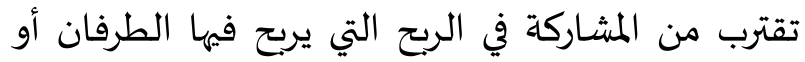

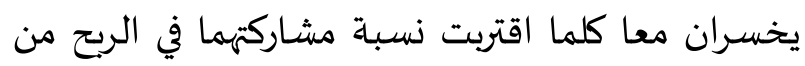
نسبة مشاركتهما في الخسارة. ولعل هذا يعطي تفسيرًا لمستند هيئة المحاسبة والمراجعة للمؤسسات المالية

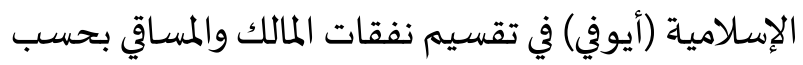
حصيهما في الإيراد وهو "أنه أقرب إلى تحقيق العدالة؛ حتى لا يقع ضرر على أحدهما لحساب صاحبه". وفي الواقع أنه يمكن تفسير التكاليف التي يتحملها

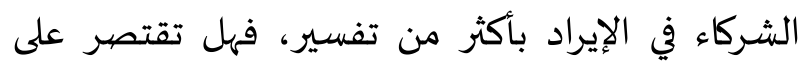
التدفقات النقدية الخارجة؟ أم ثمن المدخلات المادية

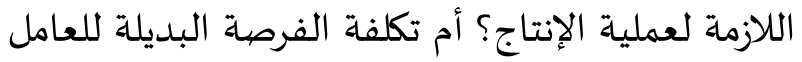

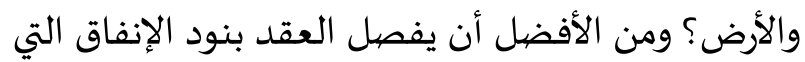

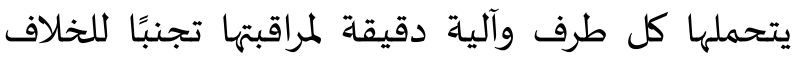
وتقليلاً للمخاطر الأخلاقية التي أشرنا لها في الفقرة (6-1). تدل الحالة الثالثة في الفقرة (6-3-3) أنه إذا كانت نسبة المشاركاة في التكاليف ثابتة ولكن متغيرة في الإيراد، فسيكون هناك تفضيل لطرف على آخر في الإيراد. وإذا ما سمحنا بتغير نسبة المشاركة في التكاليف فسيكون بالإمكان تقوية هذا التفضيل خاصاة في حال تدني مستوى لإدائ الإيراد عن حد معين. فإذا سمح عقد المشاركة في الإيراد

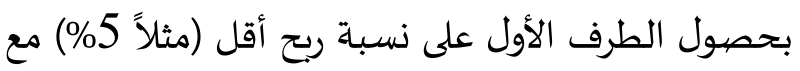
تحمل نسبة تكاليف أعلى (مثلاً 20\%) إذا قل الإيراد عن حد معين (مثلا M) فإن ذلك يقلل من مخاطر الطرف 
وعند التعمق في موضوع التكاليف التي يمكن أن تتحملها الحكومة لتحفيز القطاع الخاص، نجد أنها تنقسم

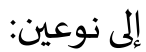
1. تكاليف تلتزم الحكومة بتحملها بشكل مباشر، وتصبح بالتالي ضمن التزاماتها الجارية. والملاحظ أنه كلما

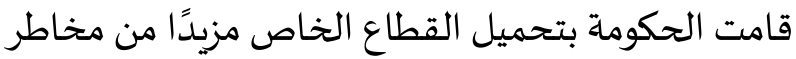
الإيراد، فإن القطاع الخاص سيطالب الحكومة بتحمل نسبة أكبر من التكاليف المباشرة. ويوضح الخط الأزرق التران الفاتح المتصل في الشكل رقم (8) العلاقة الطردية بين المخاطر المحولة من القطاع العام للخاص ومساهمة الحكومة المباشرة في تحمل تكاليف المشروع.

2. تكاليف محتملة تلتزم الحكومة بدفعها في حال انخفاض الإيراد الفعلي عند حد معين. والملاحظ أنه كلما

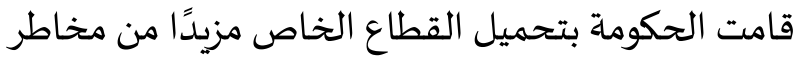

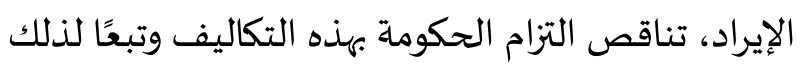

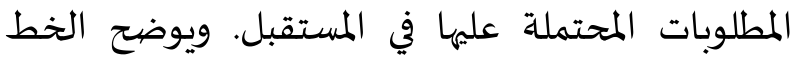
الرمادي في الشكل رقم (8) العلاقة العكسية بين المخاطر المحولة من القطاع العام للخاص والمطلوبات المحتملة من

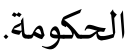
ونظرًا للعلاقة المتضاربة بين المخاطر المحولة من القطاع العام للخاص وهذين النوعين من التكاليف، فإن لعان الحكومة تحتاج للمفاضلة بين خياري تحمل التكاليف المباشرة أو المحتملة؛ إذ كلما زادت مساهمتها المباشرة في التكاليف قلت حاجتها للالتزام بمطلوبات محتملة والعكس الدس التهاد صحيح.وتختار الحكومة عادة النسبة المثلى لتوزيع المخاطر التي تكون عند النقطة الدنيا على منحنى التكاليف الصافية الإجمالية الذي يشمل التكاليف المباشرة والمحتملة (الخط الأزرق الغامق في الشكل رقم 8).
تطبيقه، هو أن نأخذ بالحسبان درجة الظن في حصول

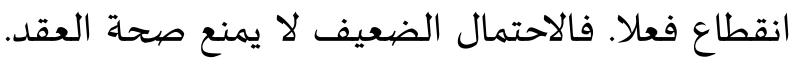

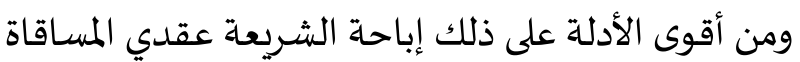
والمزارعة مع احتمال انقطاع الشركة فيهما. لأنه احتمال ضئيل مرجوح في ميزان الشريعة إذا قورن بالدخل الحقيقي المرجو من إباحة هذه العقود الإنتاجية التي تشغل موارد بشرية ومادية قد تبقى لولاها معطلة. كما لإنا

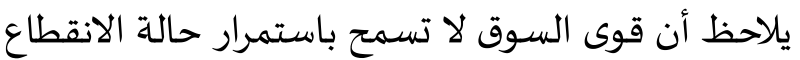
لو وقعت، لأن الطرف المغبون لن يرضى تجديد العقد لفترة مقبلة إلا بزيادة حصته،، تحوطا من تكرار الانقطاع. وننبه هنا إلى أن عقد المشاركة في الإيراد يتيح للطرفين

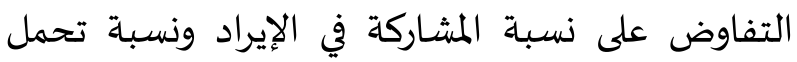
التكاليف بشكل مستقل، وليس على الريح الناتج عهما. وبالطبع سيأخذ كل طرف في الحسبان نتائج المفاوضات التيات التهات

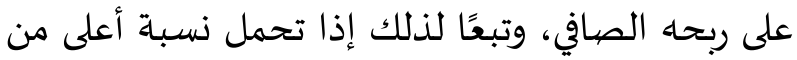
التكاليف فالرشد الاقتصادي يقتضي أن يطالب بنسبة أعلى من الإيراد. والتساؤل في الفقرة السابقة له علاقة بهذا

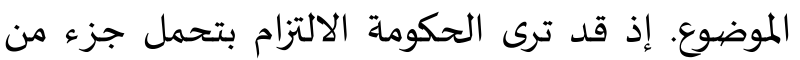

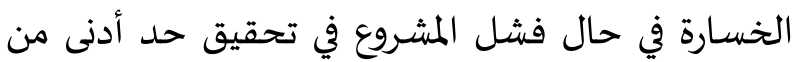
الإيراد. وهو ما يعني أهها قد تقبل بتحمل تكلفة أعلى وإيراد

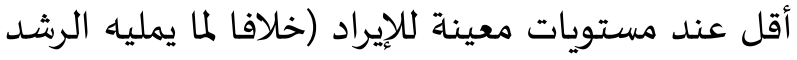
الاقتصادي على القطاع الخاص) بهدف تحفيز القطاع

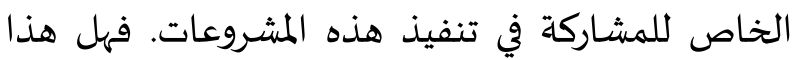
سائغ شرعًا؟ وهل من السائغ أيضًا أن تسهم الحكومة إندات بضمان حد أدنى من الإيراد بطريق غير مباشرة من خلال

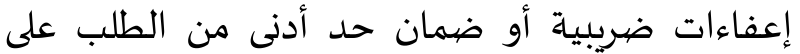

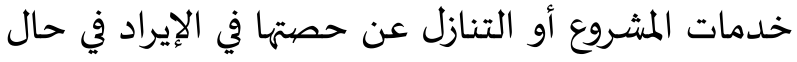

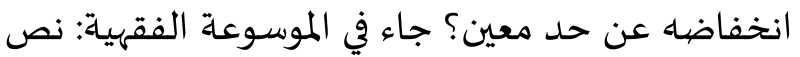
المالكية على جواز أن تكون الثمرة كلها للعامل أو المالك. وخرج ذلك على أنه منحة لا مساقاة (الموسوعة الفقهيية، (121/37 
شكل (8): العلاقة بين المخاطر المحولة من القطاع العام للخاص والتكلفة المتوقعة على القطاع العام

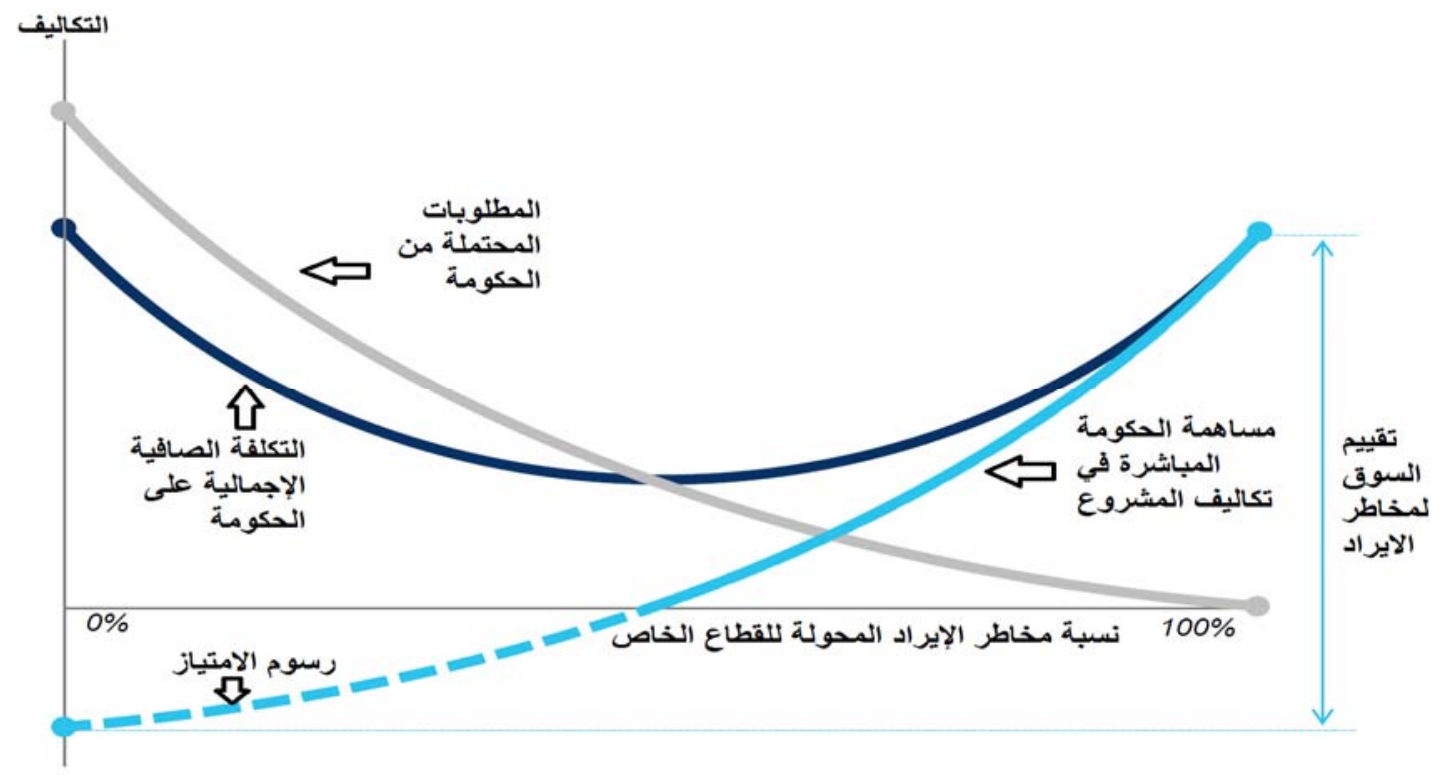

المصدر: من إعداد الباحثين

يغطي إيراد الطرف الثاني التكاليف المتغيرة وهامش الريح

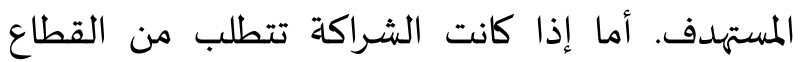
الخاص إنشاء مرافق بنية أساسية تتطلب استثمارًا

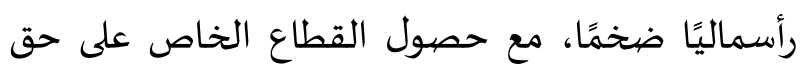
امتياز طويل نسبيًا لتشغيل المشروع ليتمكن من استعادة الماديا

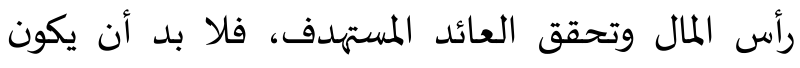

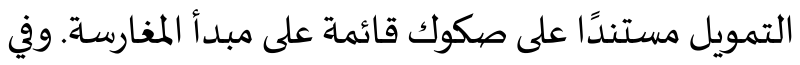

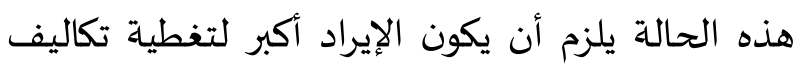

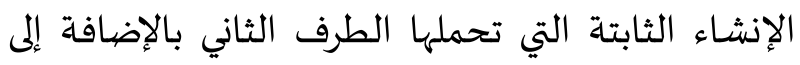
تكاليف التشغيل والصيانة المتغيرة وهامش الريح

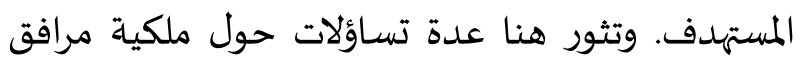

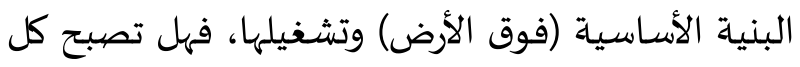

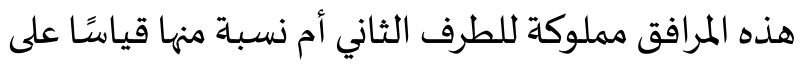

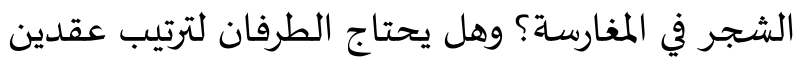

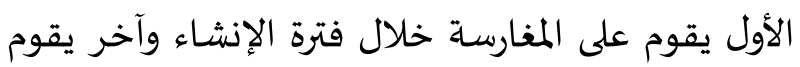

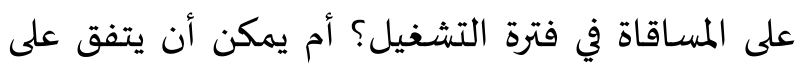

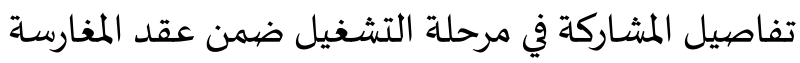

وعليه، فإن من التحديات التي تواجه هيكلة الصكوك

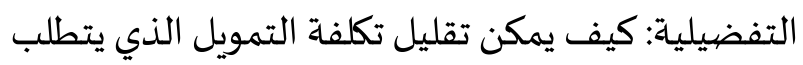
عادة تقليل المخاطر التي يتحملها حملة الصكوك؟ ويلحظ أن العطاءات تتنافس على تقديم أعلى رسوم امتياز في حال

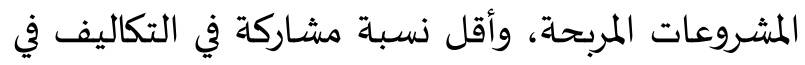
حال المشروعات غير المربحة. وإذا ما قبلت الحكومة بمبدأ

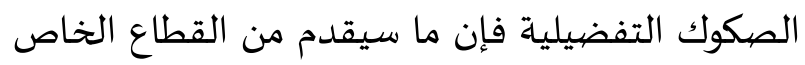

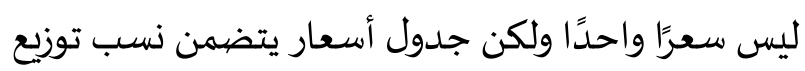
الإيرادوالتكاليف بناء على مستوياتها المتوقعة.

والمسألة الأهم فيما يتعلق بالتكاليف عند الحديث عن مشروعات الشراكة بين القطاعين العام والخاص، هي نوعية التكاليف التي تتطلها هذه المشروعات، وتبعًا لذلك التكات

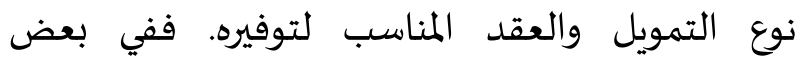
المشروعات تبدأ الشراكة بعد إنشاء مرافق البنية الأساسية من قبل الحكومة ويقتصر دور القطاع الخاص المبراء على التشغيل والصيانة فقط، ويناسبها التمويل من خلال صكوك قائمة على مبدأ المساقاة. وفي هذه الحالة يلزم أن الن 
يوجب على من يقول بالجواز أن يقدم دليلاً من قياس أو سواه. ونستبعد جواز ذلك على إطلاقه، بل لابد من قيود - تحتاج صياغتها إلى مزيد نظر - أهمها ألا تؤدي المشاركة في الإيراد إلى ضمان رأس المال وزيادة فوقه لحملة

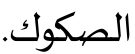

وتسهيلاً لدراسة هذا المسألة، نُقرّهها بالمثال الآتي: نفترض إصدار شركة الكهباء صكوك مشاركة في الإيراد

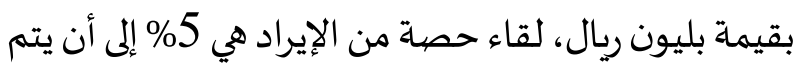
سداد أصل مبلغ التمويل (بليون ريال) وربح محدد (مثلاً

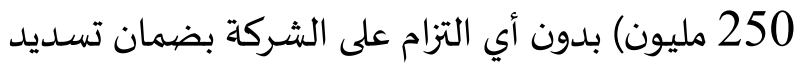

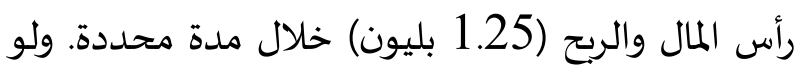
افترضنا أن متوسط إيراد الشركة السنوي خمسة بلايين ريال، فإن 5\% من الإيراد تساوي 250 مليون ريال؛ وهو إيراد الشركة ما يساوي 25\% من رأس مال الصكوك. وبالتالي الئي يمكن تسديد رأس المال والريح خلال خمس سنوات المات وقد تكون

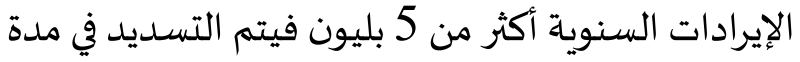
أقل من خمس سنوات، وقد تكون أقل فيمتد التسديد إلى الى أكثر من خمس سنوات. وقد تتعرض الشركة للإفلاس والتوقف عن النشاط ويخسر حملة الصكوك بحصولهم

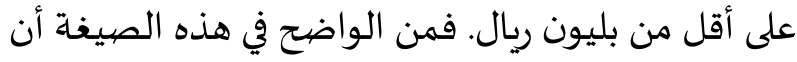
الشركة لا تضمن لا رأس المال ولا الريح، ولا يعد أي أي منهما

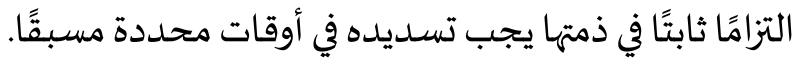

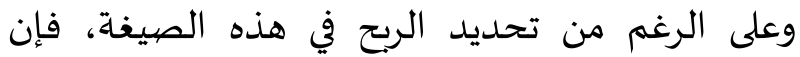
المخاطرة تظل موجودة؛ لأن الريح الفعلي قد يكون أكبر أو

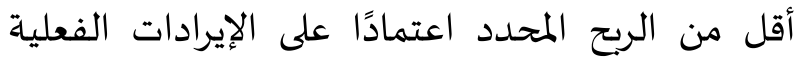
للشركة التي قد تعجل أو تؤخر حصول حملة الصكوك الماند على هذا الريح. بالإضافة إلى ذلك، تتميز هذه الصيغة الصية بالمرونة التي تسمح بالتحكم في مدة الصكوك المتوقعة بتغيير حصاة حملة الصكوك من الإيراد والريح المحدد في ضوء المتوسط المتوقع للإيرادات السنوية للشركة.
الأصلي؟ وحيث إن هذه المشروعات تتضمن الإنشاء ثم التشغيل، فهل من الممكن تطوير عقد جديد يناسبها

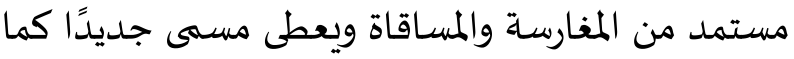
تم ابتكار عقد المساطحة؛ وإذا كان ذلك ممكنًا، فما المسبى المقترح الذي يتناسب مع طبيعة إنشاء هذه الأصهول

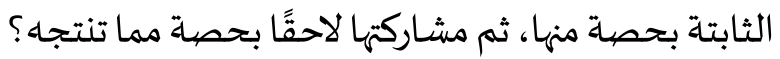
وأخيرًا، من الواضح أن الممول في هيكل صكوك المشاركة في الإيراد المقترح في هذا البحث هو صاحتب الماحب العمل (الطرف الثاني). أي أن حملة الصكوك لا يقدمون المال

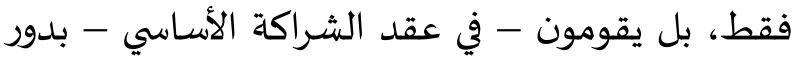

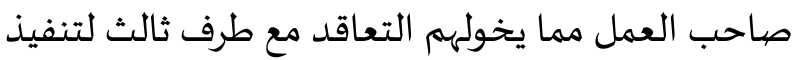
العمل. وهذه الهيكلة تبعد الصك عن الإشكالات التي يمكن أن ترد في حال اقتصار دور حملة الصكوك على التمويل النقدي فقط، كما هو الحال في صيغة تمويل مشروعات رأس المال الجريء برأس مال نقدي، المذكورة في القسم (4) من البحث. مع ذلك تظل إمكانية اقتصار دور حملة الصكوك على المساهمة النقدية فقط والمشاركة في الإيراد أحد الخيارات التي ينبغي أن تدرس بعمق لتقييم مدى

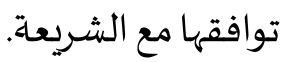
ومن الواضح في هذا السياق أن الأدلة الشرعية أجازت دون ربب لمن قدم مالاً نقديًا حصةًً من الريح كما في الراني المضاربة، ولمن قدم عينًا كالأرض الزراعية أو الحديقة المثمرة، حصة من النتاج كما في المزارعة والمساقاة. والطرف الآخر في هذه الحالات كلها يقدم عملاً، وقد يقدم مالاً أيضا كما في المساقاة (الموسوعة الفقهية، 122/37 الماتيات 125)، وفي صور للمزارعة أجازها البعض ومنعها آخرون من كبار الفقهاء (الموسوعة الفقهية، 65/37-68). غير الفرارعائ أننا لم نطلح على نص شرعي أو كلام صريح من أحد أعلام

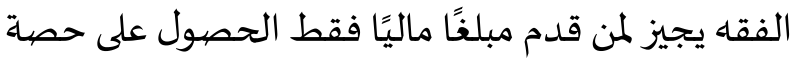
من الإيراد وليس من الريح. وهذا ليس دليلاً على المنح، لكنه 
ضامنون نتائج ذلك تجاه الطرف الأول ومسؤولون تجاهـ دون المقاول. ثم لههم أن يرجعوا على المقاول بما نابهم. والنتيجة هي أن صيغة تمويل تمنح حصية من الإيراد لمن يقدم فقط مبلغا نقديًا أو سلعة مثلية، هي صيغة مشتبهاة فقهًا، وتفتقر إلى مزيد تقييد لتخلو من الشبهاة. لكن إن اقترن مع المال تقديم عمل ينفذ بتكليف ثالث هو المقاول من الباطن، فهي صيغة لها حظ من النظر، وهي جديرة بمزيد التمحيص.

\section{7 - ملاحظات ختامية:}

بين البحث الإمكانات الواعدة لصيغة المشاركة في الإيراد وخاصة في تمويل مشروعات البنية التحتية المدرة للدخل. وقد توصل البحث إلى عدد من النتائج المهمة وأثار

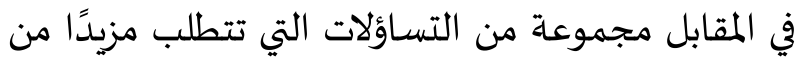

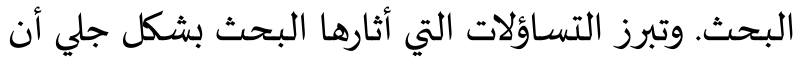

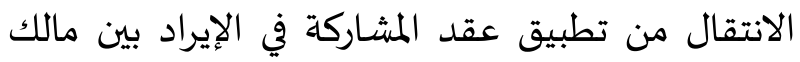
الأرض والمزارع أو المساقي أو المغارس إلى المشاركة بين الحكومة والقطاع الخاص في مشاريع إنشـاء البنية التحتية

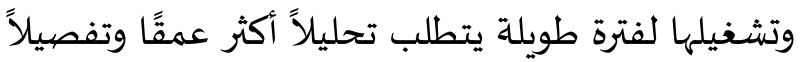
بسبب تعدد الأطراف وتنوع التكاليف وطول فترة التمويل. ويلقي هذا التركيب بظلاله على آلية تسعير منتجات صكوك المشاركة في الإيراد، والتي تتطلب تحليل قيمة المشروع باتباع عدة خطوات تبدأ بتحديد وجمع البيانات التي تمثل مدخلات أساسية للتحليل وهي بنود الإيراد والتكلفة المتوقعة خلال مدة المشروع، ثم استخدام

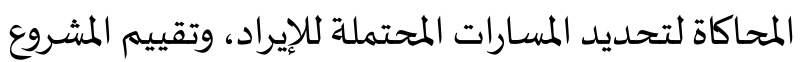
في كل مسار محتمل مع وبدون الخيارات الحقيقية التي

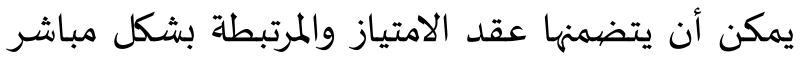

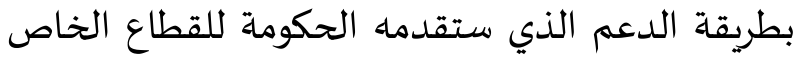
(أنظر على سبيل المثال: Ashuri et al., 2010 ). ويعد المبرد تسعير الصكوك التفضيلية المشاركة في الإيراد أحد
ولنظهر كيف يمكن لهذه الصيغة أن تؤدي أحيانا إلى

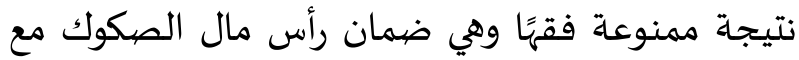

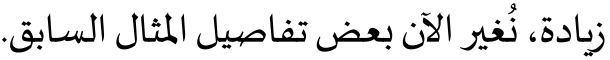

هب أن الشركة نفسها تعاني من شح في السيولة وارتفاع في النفقات الجارية، وتحتاج لتمويل هذه النفقات وليس لزيادة طاقتها الإنتاجية (رأس المال الثابت) ومبيعاتها. وللحصول على التمويل المطلوب قررت الشركة طرح صكوك بقيمة 30 مليون ريال فقط لقاء حصة 5 5 من من أن الإيراد إلى أن يتم سداد أصل مبلغ التمويل (30 مليون ريال) وربح محدد (مثلاً 6 مليون ريال) بدون أي التزام على الى الى

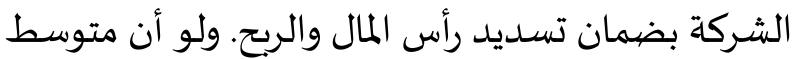
الإيراد السنوي للسنين القريبة السابقة كان 200 مليون ريال، فإن 5\% من هذا الإيراد المتوقع تساوي 10 مليون

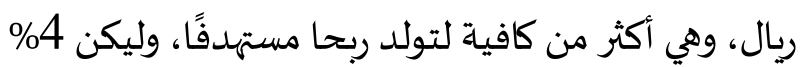
سنويا لحملة الصكوك، ولتسمح بإطفاء الصكوك بقيمتها الأصلية خلال أقل من 5 سنوات.

ومع أن تقلّب الإيرادات ينفي التيقن من وقوع الضهمان

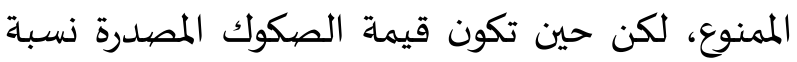
يسيرة من متوسط الإيراد السنوي المنتظر، فغالب الظن هو وقوع الضمان الممنوع. ومعلوم فقهًا أن غلبة الظن تبنى

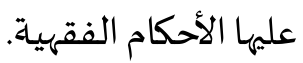

على أن هناك اعتبارًا لا يمكن إغفاله قد يفسح مجالاً للنظر في الإباحة وهو ما سبق أن ذكرنا من أن حملة

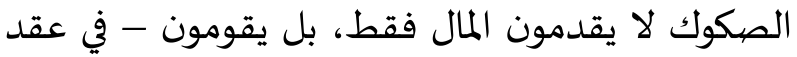
الشراكة الأساسي - بدور صاحب العمل مما يخولهم التعاقد مع طرف ثالث لتنفيذ العمل. ومع أنهم ينفذون العمل بتكليف ثالث هو المقاول من الباطن، لكنهم ضامنون شرعًا لنتيجة عمله، فلو خان أو قصر فإنهم 
الأسواق المالية الإسلامية.

الرياض، المملكة العربية السعودية. تم استرجاعاه من: https://books.google.com.sa/books?id=topLBAAAQBAJ

هيئة المحاسبة والمراجعة للمؤسسات المالية الإسلامية

(1424هـ) المعيار الشرعي رقم 17: صكوك الاستثمار، في

النسخة الإلكترونية للمعايير في موقع الهيئة

(aaoifi.com) ) المنامة، البحرين.

هيئة المحاسبة والمراجعة للمؤسسات المالية الإسلامية

(1424هـ) المعيار الشرعي رقم 50: المساقاة، في النسخة

الإلكترونية للمعايير في موقع الهيئة (aaoifi.com)،

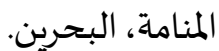

وزارة الأوقاف والشؤون الإسلامية (1407هـ)، الموسوعة

الفقهية، الكويت، الطبعة الثانية.

Ashuri, B., Kashani, H. and Lu, J. (2010), Financial Valuation of Risk and Revenue Sharing Options in Build-Operate-Transfer (BOT) Highway Projects, Working Paper Proceedings, Engineering Project Organizations Conference, South Lake Tahoe, California, November 4-7, 2010

Asian Development Bank, ADB, (2016), Philippines: Management of Contingent Liabilities Arising From Public-Private Partnership Projects. Retrieved from: https://www.adb.org/sites/default/files/publication/217 426/phi-contingent-liabilities-ppps.pdf

Dubai International Financial Centre (DIFC), (2009), Sukuk Guidebook, Dubai. Retrieved from: https://www.difc.ae/files/1014/5508/7896/islamic.pdf

Khan, Waqar M. (1989). Towards an Interest-Free Islamic Economic System, Journal of King Abdulaziz University: Islamic Economic, Vol. 1, pp. 3-38.

Lighter Capital (2017), Lighter Capital website: www.lightercapital.com, visited on June 26, 2017.

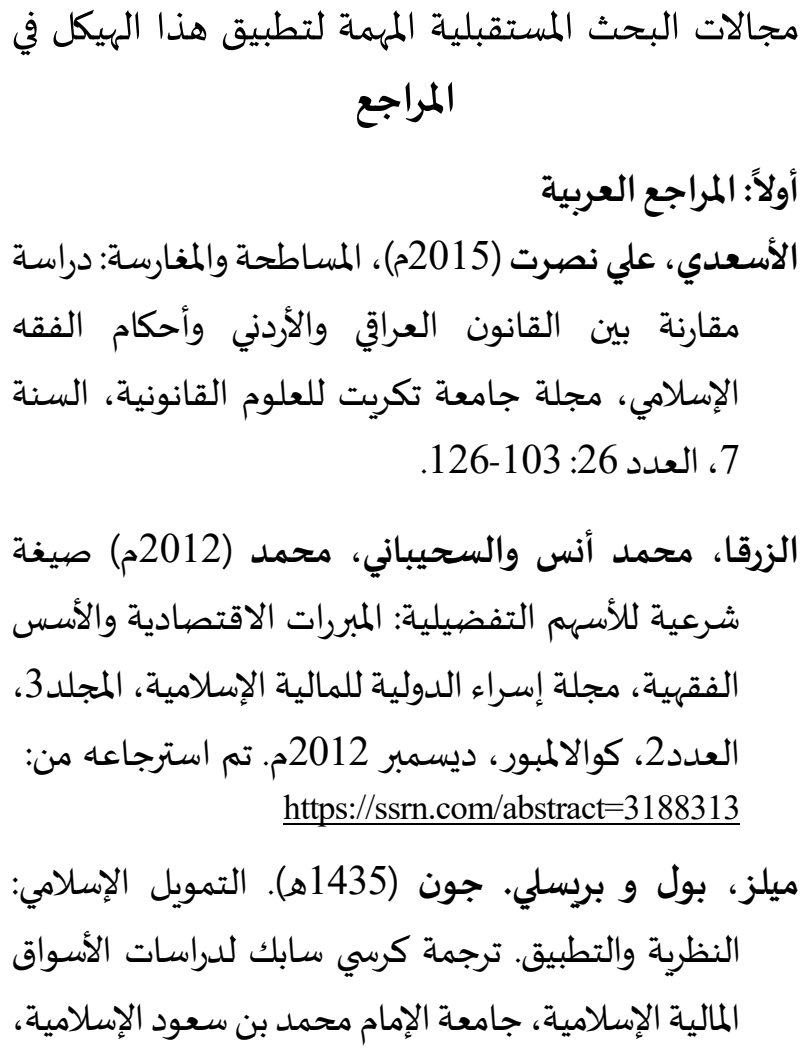

\section{ثانيًا: المراجع الأجنبية}

Sen D. (2016), Sharecropping in theory and practice: A selective review, Understanding Development: An Indian Perspective on Legal and Economic Policy. 5372

Singh, N., (1989). Theories of sharecropping. In: Bardhan, P. (Ed.), The Economic Theory of Agrarian Institutions. Clarendon Press, Oxford.

Stiglitz, J. (2013), Selected Works of Joseph E. Stiglitz Volume II: Information and Economic Analysis: Applications to Capital, Labor, and Product Markets, Oxford University Press

Verdouw, W. (2015), Sharing Risk and Revenues from PPPs: Perspectives from current practice in the road sector, International Institute for Sustainable Development, Canada

Zarqa, A. (2016), Islamic Finance: The Journey to the Present, and Potential Participatory Modes, 4th International Conference on Islamic Business, International Islamic University Islamabad (IIUI), Islamabad, February, $21 \& 22$. 


\section{Translation of Arabic References}

Accounting and Auditing Organization for Islamic Financial Institutions (AAOIFI) (2003) Shari'ah Standard No. 17: Investment Sukuk, Online version of Shari'a standards on the AAOIFI.com website, Manama, Bahrain.

Accounting and Auditing Organization for Islamic Financial Institutions (AAOIFI) (2003) Shari'ah Standard No. 50: Musaqa (Irrigation contract), Online version of Shari'a standards on AAOIFI.com website, Manama, Bahrain.

Al-Assadi, Ali Nasrat (2015), Musataha (Land Development Lease) and Magharsa (Plantation Contract): A Comparative Study between Iraqi and Jordanian Law and Islamic Jurisprudence, Tikrit University Journal of Law, Year 7, No. 26: 103-126.
Al-Zarka, Muhammad Anas and Al-Suhaibani, Muhammad (2012) Shari'ah-compatible Preference Shares: The Fiqh Basis and Economic Rationale, ISRA International Journal of Islamic Finance, Volume 3, Issue 2, Kuala Lumpur, December 2012. Retrieved from: https://ssrn.com/abstract=3188313

Mills, Paul and Presley. John (2014). Islamic Finance: Theory and Practice (Arabic Translation), SABIC Chair for Islamic Financial Market Studies, Imam Muhammad Bin Saud Islamic University, Riyadh, Saudi Arabia. Retrieved

from: https://books.google.com.sa/books?id=topLBAAAQBAJ

The Ministry of Awqaf and Islamic Affairs (1407), Encyclopedia of Islamic Jurisprudence, Kuwait, $2^{\text {nd }}$ edition. 
محمد أنس بن مصطفى الزرقا حصل على الإجازة في الحقوق بمرتبة الشرف من جامعة دمشق عام

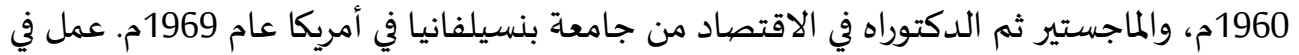

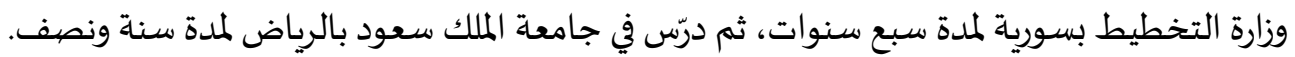

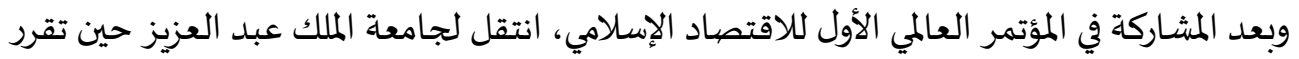

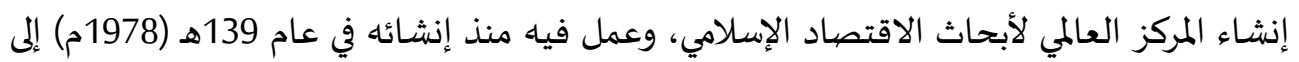

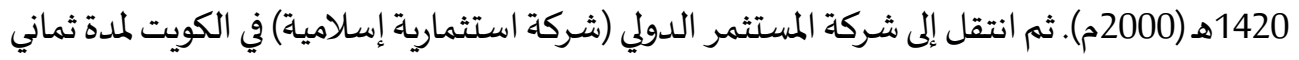

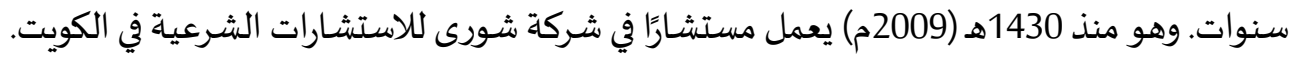

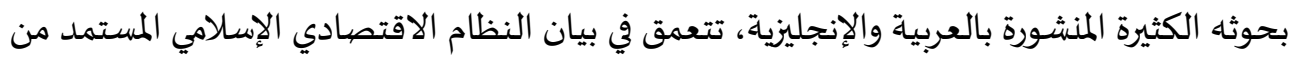

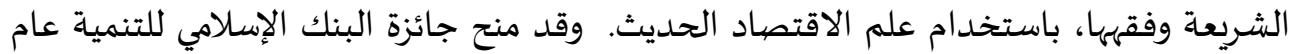

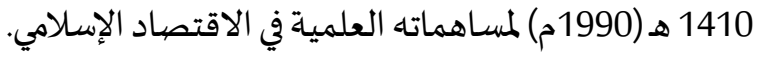
البريد الإلكتروني: هـanaszarkagmail.com

محمد بن إبراهيم السحيباني حصل على البكالوريوس ثم الماجستير في الاقتصاد الإسلامي من جامعة

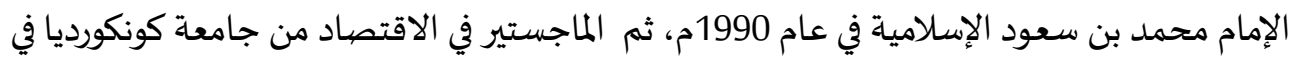

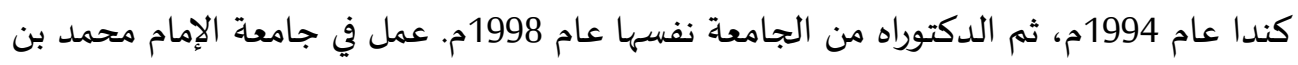

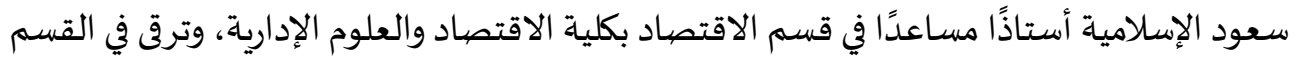
حتى حصل على درجة الأستاذية في عام 2008م. تولى عدة مناصب في في كلية الاقتصاد والعلوم الإدارية الإدادية

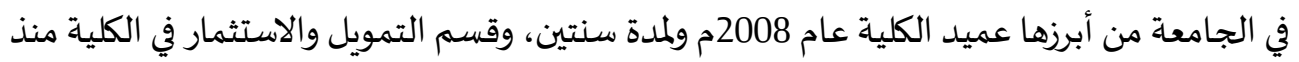

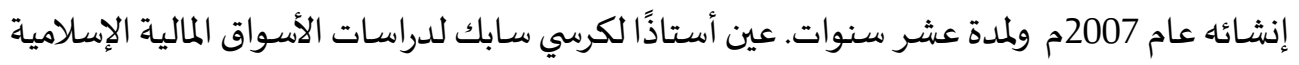

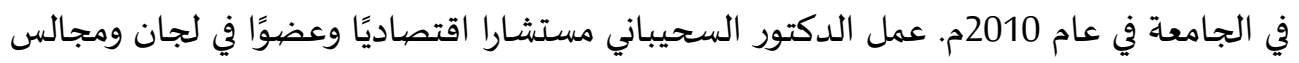

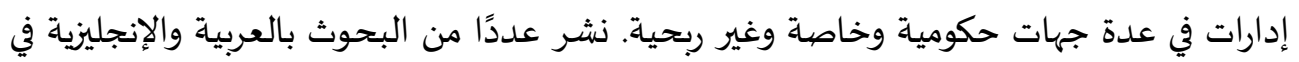

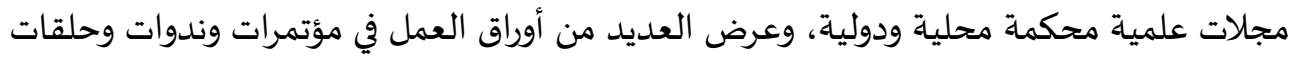

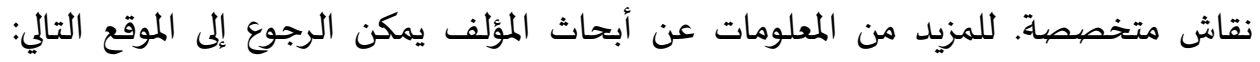
https://scholar.google.com/citations?user=iQxnL1cAAAAJ\&hl=en البريد الإلكتروني:

نادر أحمد النيفر أستاذ مشارك في المالية حصل على شهادة الدكتوراه من جامعة صفاقس سنة

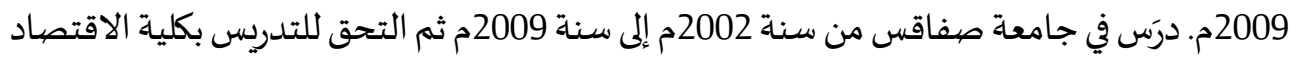

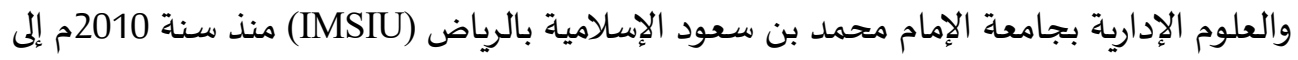

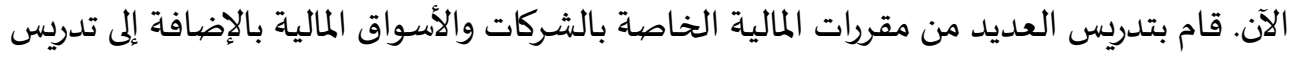

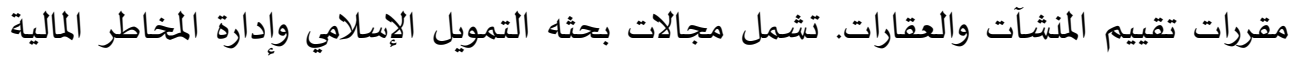

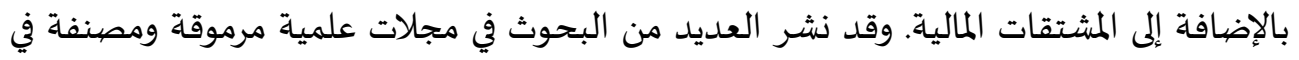

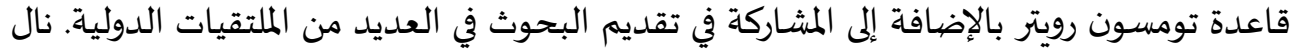

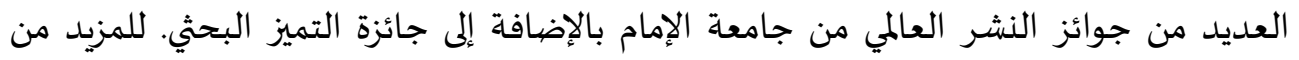

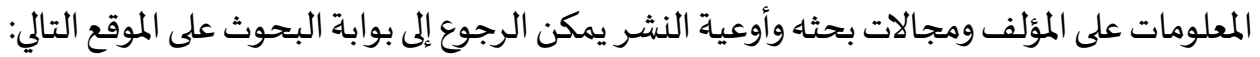
. https://www.researchgate.net/profile/Nader_Naifar البريد الإلكتروني: doctoratnader@yahoo.fr. 


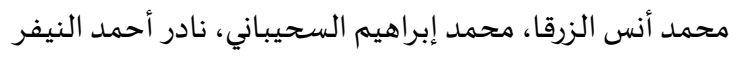

\title{
Preference Sukuk to Share Revenue
}

\section{Muhammad Anas Zarqa, Mohammed Al-Suhaibani, Nader Naifar}

\author{
Chief Consultant, Shura Company, Kuwait \\ Professor; Associate Professor \\ Department of Finance and Investment, \\ Faculty of Economics and Administrative science, Al-Imam University Riyadh
}

\begin{abstract}
Revenue Sharing (RS) or output sharing financing contracts are extensions to some contracts known in Islamic fiqh and practiced from antiquity, such as muzara'a (sharecropping), musaqah (financing and management of a fruit orchard) and mugarasah (plantation in return for a share of the trees). In spite of their promising potential in financing income-generating infrastructure projects, RS contracts have yet to be applied in Islamic Finance. This paper briefly reviews literature in conventional economics on RS and their modern application to Public-Private Partnership (PPP) in infrastructure projects. The paper suggests a novel Shari'ah-compliant sukuk structure based on RS, with extra flexibility through giving preference to one party over another in sharing revenue and/or bearing certain costs. This permit attracting to the same project parties having different risk appetites and expectations about the project's returns. The paper highlights the significance and potential applications of the fact that $\mathrm{RS}$ in general, and the suggested sukuk structure in particular, reduce information asymmetry;-and thus, minimize the need for agent monitoring and associated costs, as compared to profit sharing contracts. Certain economic and Sharia issues arising in such potential applications are outlined for further research.
\end{abstract}

Keywords: sukuk, revenue sharing, sharecropping, musaqah, mugarasah, financing infrastructure projects, public-private partnerships, information asymmetry.

JEL Classification :H54, D86, D82

KAUJIE Classification :K13, K6, R35 